\title{
Micro and Nanogels for Biomedical Applications
}

\section{Biyomedikal Uygulamalar için Mikro ve Nanojeller}

\author{
Mehmet Can $^{1 \odot}$, Olgun Güven ${ }^{\circledR}$, Nurettin Şahiner ${ }^{1,3^{*} \odot}$ \\ ${ }^{1}$ Department of Chemistry, Çanakkale Onsekiz Mart University, Çanakkale, Turkey. \\ ${ }^{2}$ Department of Chemistry, Hacettepe University, Ankara, Turkey. \\ ${ }^{3}$ Department of Ophthalmology, University of South Florida, Tampa, FL, USA.
}

\section{ABSTRACT}

M icro and nano hydrogels developed from natural and synthetic polymers have garnered great deal of attention in scientific and industrial realms due to their higher surface area, degree of swelling and active material loading capacity, softness and flexibility, as well as their similarity to natural tissues. Particularly, biocompatible, non-toxic, and biodegradable micro/nano vehicles with tailor made design and functionalization facilitates their use with excellent feasibility for a variety of biomedical applications such as tissue engineering, bioimaging and drug delivery. However, these platforms require rational design and functionalization strategies to cope with barriers of in vivo environment to pass into clinical use. Firstly, an ideal carrier should be biocompatible, and capable of evasion from immune elimination, specifically target at desired sites and sustainably release the therapeutic cargo in response to microenvironment conditions. Despite the few setbacks in micro/nano vehicle design and several successful formulations translated to clinical use and majority of the carries are yet to achieve complete success for all biological criteria. In this review, design and functionalization strategies of micro and nanogels have been summarized. Also, the recent progress in biomedical applications of microgels and nanogels have been outlined with a primary focus placed on drug and biomolecule delivery applications.

\section{Key Words}

Microgel, nanogel, drug delivery, biomedical applications.

\section{öz}

\begin{abstract}
oğal ve sentetik polimerlerden geliştirilen mikro ve nano hidrojeller, yüksek yüzey alanı, yüksek derecede şişme, yüksek aktif madde yükleme kapasiteleri, yumuşaklık esneklik ve doğal dokulara benzerlikleri nedeniyle bilimsel ve endüstriyel alanda büyük ilgi görmüştür. Özellikle, biyouyumlu, toksik olmayan ve biyobozunur mikro/nano taşıyıcıların uygulamaya özgü tasarım ve fonksiyonelleştirilebilme olanakları, doku mühendisliği, biyo görüntüleme ve ilaç salınım uygulamaları gibi çeşitli biyomedikal uygulamalar için mükemmel bir engelleri sunmaktadır. Bununla birlikte, bu platformların in vivo ortamlardaki biyolojik engelleri aşabilmesi ve klinik uygulamalarda kullanıma girebilmesi için rasyonel tasarım ve işlevselleştirme stratejileri gerekmektedir. İlk olarak, ideal bir taşıyıcı biyo-uyumlu olmalı ve bağışıklık sisteminin eliminasyonundan kaçabilmeli, özellikle de istenen bölgeleri hedeflemeli ve ortam koşullarına duyarlı olarak ilacı sürdürülebilir bir şekilde salabilmelidir. Mikro/nano malzeme tasarımında küçük sorunlara rağmen klinik kullanıma giren birkaç başarılı formülasyon mevcuttur. Bu taşıyıcıların çoğu, tüm biyolojik kriterler için henüz tam bir başarı sağlayamamışlardır. Bu derlemede, mikro ve nanojellerin tasarım ve işlevselleştirme stratejileri özetlenerek mikro- ve nanojellerin biyomedikal uygulamalarındaki son gelişmeler, ilaç ve biyomolekül salım, uygulamalarına ağılık verilerek özetlenmiştir.
\end{abstract}

\section{Anahtar Kelimeler}

Mikrojel, nanojel, ilaç salımı, biyomedikal uygulamalar. 


\section{INTRODUCTION}

t has been 100 years since Hermann Staudinger provoked a pioneering contribution in chemistry with " Uber polymerization" ("on polymerization") [1] which had deemed as the initial spurs that paved the way for a remarkable development in polymer science and technology [2]. Based on the outcomes of his seminal investigations in macromolecular chemistry, numerous polymers have been developed in practically many domains of industry ranging from food packaging to biomedical applications [2,3]. Ever since, Staudinger's efforts in understanding the polymerization of high molecular weight polymers, years of accumulated research along with discovery of new analytical techniques have led to dramatic breakthroughs in biomaterial science and nanotechnology. A number of natural and synthetic structures along with various supramolecular materials have emerged with promising capabilities including natural clay based materials [4], carbonaceous materials [5], inorganic nanoparticles [6], dendrimers [7], liposomes [8], hydrogels, and so on for biomedical use in a variety of applications e.g., theranostic and bioimaging, antimicrobial and antifouling materials $[9,10]$, and in treatment of cancers and equally pervasive disorders [11]. Beside many others, micro and nano hydrogels also called microgels and nanogels can be accounted as the products of the intensive research that were grown on those sparks fueled by Staudinger leading to the blueprints on the polymerization and also together with Husemann on polymerization of divinyl benzene and polystyrene $[12,13]$. However, the "microgel" term was used for the first time by Baker et al., in 1949 and viewed as a new class of macromolecule in the literature [14].

Micro/nano size of hydrogels, microgel/nanogels are comprised of mostly hydrophilic or amphiphilic chains of either synthetic, and natural polymers or their combinations linked by chemical (covalent) or physical (noncovalent) crosslinks into three-dimensional (3D) infinite networks. Due to their great degree of fast swelling, and high water retention ability while intactly maintaining their structures, micro and nanogels can serve as excellent tools for a wide range of biomedical applications such as reservoirs in transport and delivery of various therapeutics and biologically active molecules including vaccines, cytokines, growth factors, hormones, proteins, and genes $[15,16]$. Given the soft and flexible nature as well as mechanical and structural similarity of these platforms to natural tissues and the extracellular matrix (ECM) of cells, micro and nanogel particles with high biomimetic characters attain remarkable feasibility in scaffolding, attachment, and culturing of cells whereby, achieve great potential in tissue engineering, cartilage repair, bone replacement, and wound dressing applications $[17,18]$. Moreover, what makes micro and nanogels particularly promising interfaces for biomedicine comes from their ease of manipulation and tailor-made adaptability of their characteristics by variation of their surface chemistry upon pre- or post-synthetic chemical modifications to induce adjustable hydrophobicity, surface charge and functional groups combined with precisely controllable particle size, porosity and degradability of the polymer matrix. All these in turn collectively endows unprecedented suitability and efficiency for encapsulating wide variety of molecules with distinct biological characters. Micro and nanogels help solubilization and homogenous dispersion of drugs in the polymer matrix, protects them from biological transformation and oxidizing microenvironment of the intra cellular milieu, mask cytotoxicity of the drugs and potential side effects that may be aroused thereof and hence provide enhanced bioavailability and treatment efficiency [15]. Besides, micro and nanogels coupled with specific ligands can achieve sustainable and stimuli-directed drug release at target sites and tissues, therefore prevent nonspecific cell toxicity and provide better therapeutic efficacy at lower doses [19]. Biomedical applications of micro and nanogels are briefly illustrated in Figure 1. Nanogels maybe discriminated from microgels with larger specific surface area and inner compartments rendering higher encapsulation efficiency of drugs with prolonged circulation and facile extravasation ability through cell membranes. Various strategies have been emerged to achieve sustainable and slow drug release as well as to prolong residence time of the particles in blood stream. Specifically, coating or conjugation of hydrophilic polymers to micro and nanogels surface such as hydroxy ethyl starch (HES), and polyethylene glycol (PEG) may provide steric hindrance to protein adsorption, additionally, entrapment of microgels and nanogels in biological membranes as camouflaging were employed to impart stealth characteristics as well as for sustained and more controlled release kinetics [20].

Despite the continuous investigations on development of micro nano architectures, it is still far from ideal translation into clinical practice as most of the particle formulations suffer from several important shortcomings that need to be circumvented such as lack of standardization 
on manufacturing due to batch variations, as well as toxicity, immunity, aggregation, unspecific spatial distribution in the host and rapid elimination from the systemic circulation [21]. Regarding the extraordinary potential of these systems in nanobiotechnology, pharmaceutical and biomedical fields as diagnostic and therapeutic agents either stand-alone or in combination with other micro/ nanomaterials in the form of multifunctional composites, the urgent need aroused the development of personalized medicines with customizable and precisely manageable characteristics that necessitated new strategies to developed and/or optimize the surfaced issues in the light of systematic approaches and multidisciplinary science and technology. In this review, we provide a general outlook to the key considerations in rational design and implementation of micro and nanogels and an update on emerging studies and techniques to fabricate and functionalize micro nano hydrogel particles focusing primarily on the most recent advancements in drug delivery applications.

\section{Methods in building up micro and nanogel networks}

Basically, micro and nanogels can be constructed by following two main strategies which rely on chemical crosslinking of precursors with stable covalent bonds and with the formation of physically crosslinked and/or reversible self-assembled or interpenetrated structures by non-covalent associations such as hydrophobic and electrostatic interactions, Van der Waals forces, hydrogen bonding and host-guest interactions between of micro and nanogel precursor components [19].

\section{Physically crosslinked microgels and nanogels}

In a general point of view, self-assembly mediated particle formation is a hierarchical process that polymeric components in the reaction microenvironment effort to ensure thermodynamically favorable equilibrium state which lead to simultaneous arrangement of the polymer chains and generate micro/nano particles. For-
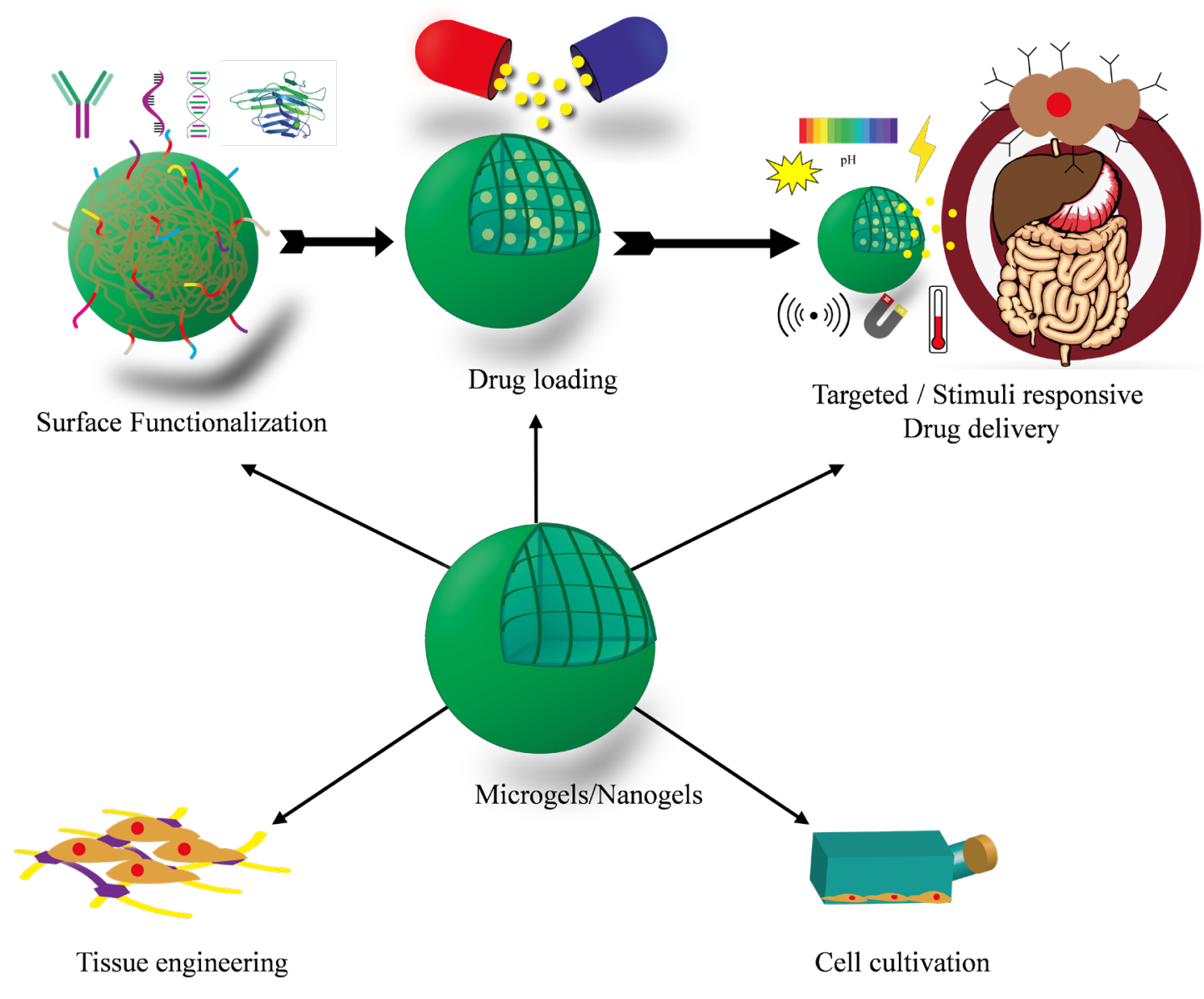

Figure 1. Biomedical applications of microgels and nanogels. 
mation of these physically crosslinked supramolecular networks is mainly driven by non-covalent weak intermolecular forces (IMFs), and the size of the resultant particles are majorly dependent on the $\mathrm{pH}$, temperature, ionic strength as well as concentration and chemical composition of the substrates used in particle preparation $[15,16]$. Self-assembly process of micro and nanogel was depicted in Figure 2a. Self-assembled nanogels were firstly introduced by Akiyoshi and colleagues, where hydrophilic pullulan polysaccharides were conjugated with hydrophobic cholesterol units and sonication of these amphiphilic polysaccharide derivatives in water yielded intramolecularly self-aggregated monodisperse particles with $25 \pm 5 \mathrm{~nm}$ sizes [22]. Moreover numerous microgels and nanogels have been reported by self-assembly process including synthetic and natural polymeric substrates such as poly(N-isopropylacrylamide) (PNIPAM) [23], poly(hydroxyethyl methacrylate) (p(HEMA)) [24], polysaccharides [25], pullulan [26], chitosan (CHI) [27-32], alginic acid [24], dextran [33,34], hyaluronic acid (HA) [35-39], starch derivatives [40], and polyphenols [41-44], proteins [45], polypeptides $[46,47]$, various amino acids [48], and DNA [30,49,50] all of which were intended for biomedical applications in delivery of various therapeutic agents including small molecules, proteins, drugs, and genes and siRNAs.

\section{Chemically crosslinked microgels and nanogels}

Chemical crosslinking is based on incorporation of permanent covalent crosslinks between monomeric or polymeric subunits of micro nanogel networks as shown in Figure 2b. Various polymerization methods have been employed in chemical crosslinking of micro and nanogels such as micromolding, ring opening polymerization, and click chemistry in addition to heterogenous controlled/living radical polymerization techniques (CRP) e.g., stable free radical polymerization, reversible addition-fragmentation chain transfer (RAFT) polymerization, atom transfer radical polymerization (ATRP) have been widely employed in micro and nano-

(a)

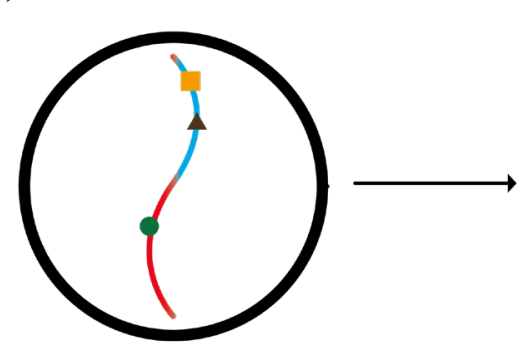

Microgel/Nanogel precursor

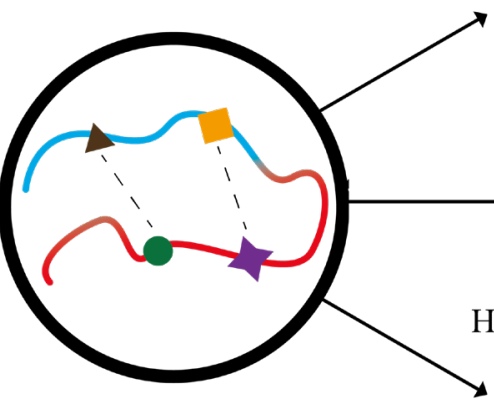

Physical crosslinking

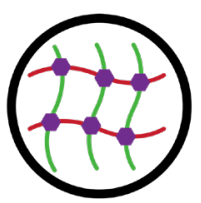

Interpenetration

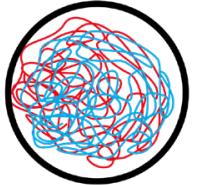

Hydrophobic interactions

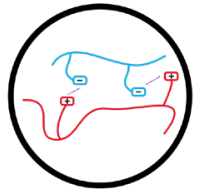

Ionic interactions

(b)

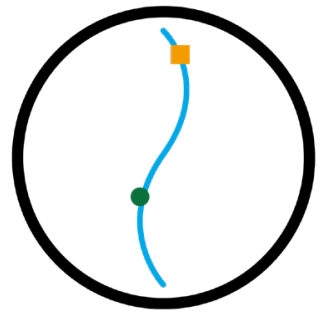

Microgel/Nanogel precursor

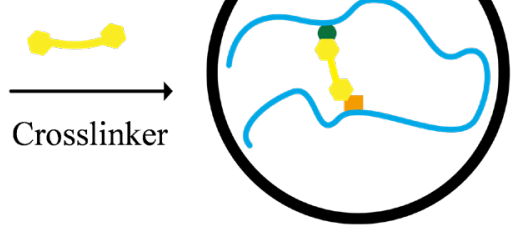

Chemical crosslinking

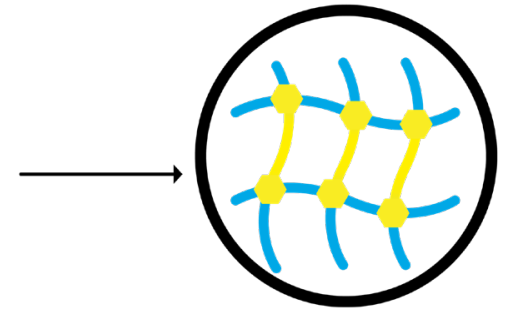

Chemically crosslinked microgel/nanogel

Figure 2. Schematic illustration of (a) physical, and (b) chemical crosslinking processes of micro and nanogel preparation. 
gel preparations as they provide a remarkable control over the molecular weight and the molecular weight distribution of generated polymer networks [51]. Alternatively, uncontrolled heterogenous free radical polymerization techniques are also widely used in synthesis of microgels and nanogels due to their ease of operation such as precipitation polymerization, dispersion polymerization, miniemulsion and microemulsion polymerization, microfluidics based polymerization, and irradiation-induced polymerization which was first introduced by Staudinger et al. in 1935 to produce submicron gels of styrene with divinyl benzene $[12,19,51,52]$. Numerous micro and nanogels have since been formulated by irradiation technique [53-55]. Among the heterogenous polymerization methods, inverse microemulsion polymerization is one of the most commonly used chemical crosslinking technique where water-in-oil (w/o) emulsion is prepared simply by mixing continuous oil phase and aqueous phase containing water soluble substrates in the presence of oil soluble emulsifying agents at above their critical micelle concentration (CMC). Consequently, thermodynamically stable microemulsion droplets are formed to serve as reactors for micro and nano sized particle formation [56]. The $\mathrm{pH}$, surfactant concentration, and feed ratio of the crosslinkers and used substrates in particles preparation are the most important parameters that have major effects on the particle size and distribution $[57,58]$. Diverse microgel and nanogel formulations have been reported by inverse microemulsion polymerization including synthetic polymers such as polyacrylamide [58], polyvinyl pyrrolidone $[59,60]$, polyethyleneimine (PEI) [61], p(NIPAM) [62], and natural biomacromolecules such as simple disaccharides: sucrose [63], lactose [64], polysaccharides: $\mathrm{CHI}$ [65], inulin [66], dextran [67], HA $[68,69]$, carboxymethyl cellulose [70,71], guar gum [72], and polyphenols; tannic acid [73], naringin [74], quercetin [75], and rutin [76].

\section{Drug Loading of micro and nanogels}

Micro and nanogels are capable of loading broad spectrum of therapeutic agents with distinct physicochemical characters such as cationic and anionic drugs, proteins, peptides, genes, siRNAs and so on. Various techniques were used in the loading of therapeutic cargos. Efficiency of loading and kinetics of drug release are predominantly determined by the selected method as well as composition of the carrier vehicle $[77,78]$. Gen- erally, three types of drug loading techniques are commonly employed for microgels and nanogel and schematically illustrated in Figure 3:

-Physical adsorption of drugs from solutions in suitable solvents,

- Chemical conjugation of drugs into polymer backbone (mostly by using spacer molecules)

-Entrapment or encapsulation of drug within the chains of microgel and nanogel matrix

\section{Drug loading by physical adsorption}

As depicted in Figure 3a physical adsorption of therapeutics onto micro and nanogel surface is driven by noncovalent IMFs. This technique is simply operated with some major limitations and considerations [19]. For example, the solvent used in adsorption process should be suitable for both drugs and micro/nano vehicles in such a way that it should provide adequate solubility to drug for desired concentration range and in the meanwhile should thoroughly homogenize the vehicles as good solvent effecting the efficiency of drug loading. Moreover, as the drug loading efficiency is directly proportional with strength of physical interactions between drug and carrier, the functional groups on the vehicle is another key factor that takes significant part in drug loading efficiency. For this reason, surface charge, area, porosity, as well as size and shape of the carriers should be well-characterized when considering using this drug loading method. Microgels and nanogels are mostly hydrophilic particles typically bearing$\mathrm{OH},-\mathrm{COOH},-\mathrm{SH},-\mathrm{SO}_{3}$, and $-\mathrm{NH}_{2}$ functional groups that can also be steadily derivatized to required functional groups upon chemical processing or by addition of desired functionalities by means of chemical modification. Carrageenan microgels reported by Sahiner et al. (2017) clearly illustrates the influence of functional groups on vehicles where rosmarinic acid (RA) was used as model therapeutic, loaded by physical adsorption onto carrageenan microgels [79]. The particles achieved 0.18 $\mathrm{mg} / \mathrm{g}$ RA loading efficiency. On the other hand, upon modification of carrageenan microgels with cationic diethylenetriamine molecules, the loading efficiency of the particles were drastically increased to about 240 fold, $43.7 \mathrm{mg} / \mathrm{g}$ RA adsorption which was anticipated to the increased binding affinity of drug for amine modified microgels. The modified carrageenan microgels exhibited $20 \mathrm{~h}$ of sustained drug release and effectively showed enhancement of loading efficiency after proper functionalization [79]. 
(a)
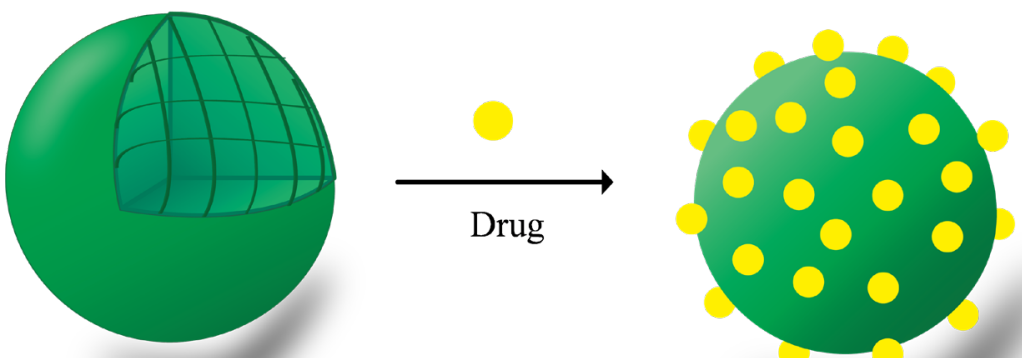

Physical adsorption

(b)

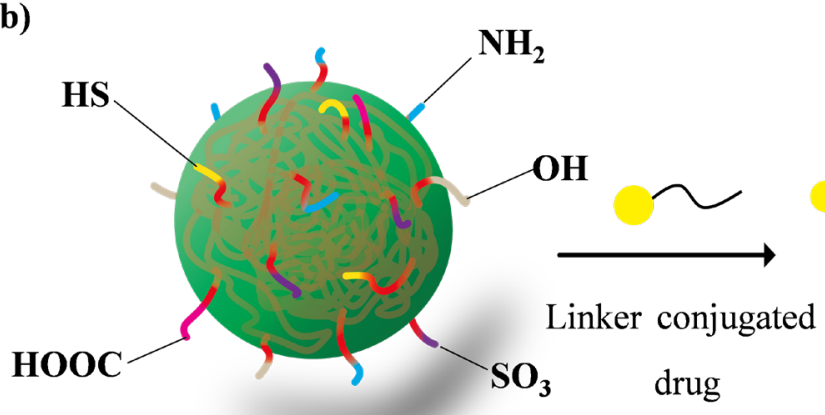

Chemical conjugation

(c)
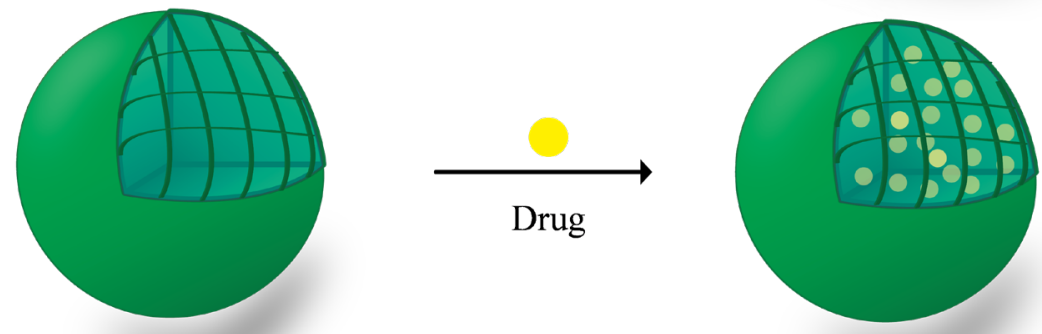

\section{Entrapment/Encapsulation}

Figure 3. Schematic depiction of drug loading process to micro and nanogels via (a) physical adsorption, (b) chemical conjugation, and (c) entrapment/encapsulation techniques.

\section{Drug loading by chemical conjugation}

In the chemical conjugation method as illustrated in Figure $3 \mathrm{~b}$, drug molecules are covalently attached to pendent functional groups on microgels or nanogels by using specific linker molecules (e.g. carbodiimide coupling) through hydrolysable or biodegradable chemical bonds in physiological conditions such as carbonate bonds, ester, anhydride, urethane, and amide bonds. Chemical conjugation mediated drug loading is perhaps the most commonly preferred loading technique mainly due to the benefits of high drug loading efficiency and stability of the loaded drugs in comparison to other techniques. Another advantages of drug conjugation are increased water solubility of drugs in physiologic environments, increased hydrodynamic volume, decreased renal filtration, aggregation, enzyme degradation and immunogenicity [80]. In a study conducted by Choi et al. (2018) dihydroxyflavone (DHF)-conjugated HA (HA-DHF) nanogels were reported with controllable particle size from 246 to 615 by changing the ratio of crosslinker 4-(4,6-dimethoxy-1,3,5-triazin-2-yl)-4-methylmorpholinium chloride (DMTMM) which was used in both crosslinking of HA units and DHF conjugation to nanogel backbone [81]. The HA-DHF nanogels were proven to achieve targeted delivery of DHF to HeLa and HepG2 cancer cell lines and accomplished $40 \%$ reduction in cell viability while they were not toxic to normal NIH3T3 cells. 


\section{Drug loading by encapsulation/entrapment}

Loading of drugs into micro and nanogels can be accomplished by encapsulation/entrapment of drug molecules during particle formation as shown in Figure $3 c$. For the chemically crosslinked particles, the drugs are entrapped within the microgel and nanogel matrix in the course of crosslinking reaction whereas for the physically crosslinked particles noncovalent interactions dominates for instantaneous arrangement and encapsulation of drugs within the polymer chains of microgel and nanogel particles as mentioned in the particle preparation methods. Hydrophilic/hydrophobic character of the drug as well as the constituents of the particles would be decisive for strength and stability of polymer-drug interactions. Therefore, the same assembly techniques can be applied for simultaneous encapsulation/entrapment of drugs into self-assembled supramolecular microgels and nanogels such as extrusion, emulsification coacervation, layer by layer assembly, spray drying and so on. In the study by Nam et al.(2013), transferrin receptor (TfR) targeted carboxymethyl chitosan $(\mathrm{CmCHI})$ micellar nanogels were prepared from 140-649 $\mathrm{nm}$ by grafting lauric acid onto $\mathrm{CmCHI}$ backbone using NHS EDC coupling and paclitaxel (PTX) was encapsulated in the nanomiccelles by hydrophobic interactions, while PEGylated transferrin was inserted to confer targeting ability for TfR receptors [82]. In vitro drug release from $\mathrm{CmCHI}$ micellar particles was investigated at three different $\mathrm{pH}$ environments, 5.2, 6.4, 7.4. PTX was revealed to follow faster kinetics at $\mathrm{pH} 5.2$ than other $\mathrm{pH}$ conditions. The PTX loaded targeted $\mathrm{CmCHI}$ micelles were shown to be effectively uptaken by various cancer cell lines (DLD-1, CoLo255,HCT 119, and SKBR3) via receptor mediated endocytosis and localized in the nuclei of cells demonstrating the efficiency of these biopolymer nanogels for cancer cell targeting.

\section{Stimuli responsive micro/nanogels and targeted drug delivery}

Micro and nanogels are excellent nominees to conventional dosage forms of drugs as they are one such class of resourceful materials with convenient suitability for biomedical applications primarily because of their softness, high water content, high surface area, and payload capacity, tunable size, biocompatibility and other advantages. Despite these superiorities, micro and nanogels still face some issues and pitfalls complicating their ideal implementation into clinical utilization such as inadequacy of efficient and stable drug encapsulation without leakage in compelling microenvironment of tissues over extended time periods and consequent toxicity issues leading to decrease in treatment efficiency [83]. Beside premature drug release, due to high surface energy of microgels and nanogels, they adsorb proteins in the serum and can be steadily opsonized and eliminated by mononuclear phagocyte system (depending on the particle size, charge, and shape) without achieving aimed drug release. Hence, these platforms require rational design strategies to surpass these restraints.

Surface properties of micro and nanogels play pivotal roles in their interactions with the surrounding cells and biomolecules, thus, proper manipulation of the particle surface is required and crucial to achieve better in vitro and in vivo performances [84]. Attachment of hydrophilic polymers such as polyethylene glycol (PEG), polyvinyl pyrrolidone, polyvinyl alcohol, and polyaminoacids are used to decrease/retard protein adsorption [85]. Alternatively, biopolymers and derivatives such as hydroxyethyl starch, dextran, $\mathrm{HA}$, and $\mathrm{CHI}$ have also been reported to give particles stealth properties [85-87]. Inclusion of these molecules creates a steric hindrance against plasma proteins, decrease adsorption and subsequent phagocytosis. In recent years, a new strategy has been emerged as another approach employed for micro/nanomaterials to increase circulation times which is coating of the particles with biomimetic molecules e.g., lipoprotein mimicking molecules, membrane proteins, peptides, and intact cell membranes $[20,88,89]$. Variety of cell membranes have been used for coating of micro/nano vehicles such as membranes of red blood cells, white blood cells, leukocytes, stem cells, cancer cells, and platelets [90-93]. In addition to coating with hydrophilic polymers and cell membranes, micro/ nano vehicles were functionalized with various ligands such as small molecules e.g., folic acid, biotin, estradiol), cell-penetrating peptides (HIV-1- derived TAT peptide), cell-targeting peptides (e.g., RGD peptide), proteins (e.g., transferrin), antibodies (e.g., prostate-specific membrane antigen, CD20 antigen,) or antibody fragments, and aptamer DNAs (e.g., sgc8 aptamer) specific to target cells and tissues stand out as a promising approach to impart target specificity as well as longer circulation half-lives [84,94-97]. Tremendous research efforts and approaches have been focused on to develop smart and on-demand customizable micro and nano hydrogels to enhance their efficiency and drug release profiles for in vivo applications [98,99]. The stimulus that microgels and nanogels are able to respond can be classified in two groups as shown in Figure 1, the first one comprises triggers present in biological barriers including variations in temperature, and $\mathrm{pH}$, or pres- 
ence of enzymes capable of breaking down specific functional groups present in the matrix of micro and nanogel network, (e.g., redox responsive disulfide bonds), while the second group of stimuli is for external manipulation of particles such as response to magnetic field, electric field, ultrasound, and irradiation [100,101].

Development of stimuli responsive and targeted hydrogel micro/nano particles have elicited new paradigms for the scope of their biomedical utilization particularly for targeted, stimulus-directed well-controlled gene, biomolecule, and drug delivery, as well as imaging and theranostic applications for cancer therapy and other diseases [102,103]. Additionally, specific ligand decorated stimuli responsive microgels and nanogels have found applications in biosensor, biomolecule separation, as well as cell maturation, and storage in tissue engineering [104]. Some of the selected stimuli responsive/targeted micro and nanogel formulations were listed in Table 1.

Table 1. Stimuli responsive/targeted microgels and nanogels used in drug delivery applications.

\begin{tabular}{|c|c|c|c|}
\hline Microgel/Nanogels & Responsive/targeted modality & Payload & References \\
\hline HA based nanogels & $\begin{array}{c}\mathrm{pH} \text { responsive }-\mathrm{CD} 44 \text { receptor } \\
\text { targeted }\end{array}$ & Doxorubicin & [109] \\
\hline HA-peptide based nanogels & $\begin{array}{l}\mathrm{pH} \text { responsive }-\mathrm{CD}-44 \\
\text { receptor targeted }\end{array}$ & Cytochrome C, SAP protein & [110] \\
\hline $\begin{array}{l}\text { DNA-biotin-streptavidin based } \\
\text { nanogels }\end{array}$ & $\begin{array}{c}\text { pH responsive - PTK-7 receptor } \\
\text { targeted }\end{array}$ & Doxorubicin & {$[11]$} \\
\hline $\begin{array}{l}\mathrm{p}(\mathrm{L}-\text { Aspartic acid }) \text { based } \\
\text { nanogels }\end{array}$ & $\mathrm{pH}$ responsive & Doxorubicin & [112] \\
\hline $\begin{array}{c}\text { Chitosan- } \mathrm{p}(\mathrm{N} \text {-vinyl } \\
\text { caprolactam) based nanogel }\end{array}$ & Thermoresponsive & 5-Fluorouracil & [121] \\
\hline $\begin{array}{c}\text { Carboxymethyl chitosan lauric } \\
\text { acid based nanogels }\end{array}$ & Transferrin receptor targeted & Paclitaxel & [82] \\
\hline K-Carrageenan based nanogels & Thermoresponsive & Methylene blue dye & [122] \\
\hline HA based nanogels & $\begin{array}{l}\text { Thermoresponsive - } \\
\text { Macrophage targeted }\end{array}$ & $\begin{array}{l}\text { di-stryl benzene derivative } \\
\text { hydrophobic fluorescent dye }\end{array}$ & [125] \\
\hline HA based microgels & $\begin{array}{l}\text { Thermoresponsive, magnetic } \\
\text { field responsive }- \text { CD44 } \\
\text { targeted }\end{array}$ & Sulfamethoxazole & [126] \\
\hline $\begin{array}{l}\text { Heparin-Chitosan based } \\
\text { nanogels }\end{array}$ & Magnetic field responsive & Bone Morphogenic Protein-2 & [139] \\
\hline $\begin{array}{l}\text { Concanavalin A- Glycogen } \\
\text { coated p(NIPAM) nanogels }\end{array}$ & $\begin{array}{l}\text { Temperature-pH-glucose } \\
\text { responsive - Transferrin } \\
\text { receptor targeted }\end{array}$ & Doxorubicin & [140] \\
\hline $\begin{array}{l}\text { Poly(2-(pyridin-2-yldisulfanyl) } \\
\text { ethyl acrylate) based nanogels }\end{array}$ & $\begin{array}{l}\text { Redox- } \mathrm{pH} \text { responsive - } \alpha \mathrm{v} \beta 5 \\
\text { integrin targeted }\end{array}$ & Doxorubicin & [142] \\
\hline $\begin{array}{c}\text { p(NIPAM)-p(acrylic acid) based } \\
\text { nanogels }\end{array}$ & Redox-pH responsive & Doxorubicin & [143] \\
\hline Chitosan-p(acrylic acid) based & Redox-pH responsive & Doxorubicin & [144] \\
\hline $\begin{array}{c}\text { Chitosan-p(HEMA) based } \\
\text { nanogels }\end{array}$ & Redox-pH responsive & Doxorubicin & [145] \\
\hline $\begin{array}{l}\mathrm{p}(\mathrm{NIPAM}) \text {-sulfobetaine } \\
\text { methacrylate- methylallyl } \\
\text { amine based }\end{array}$ & Temperature-redox responsive & $\begin{array}{l}\text { Indocyanine green - } \\
\text { Doxorubicin }\end{array}$ & [146] \\
\hline $\begin{array}{l}\text { PEO-b-poly(disulfide-alt- } \\
\text { nitrobenzene)-b-PEO based } \\
\text { nanogels }\end{array}$ & Redox-irradiation responsive & Nile Red dye & [147] \\
\hline $\begin{array}{l}\text { Poly(2-(dimethylamino)ethyl } \\
\text { methacrylate) based nanogel }\end{array}$ & $\begin{array}{l}\text { Temperature-pH-redox- } \\
\text { irradiation responsive }\end{array}$ & Coumarin - Rhodamine B & [148] \\
\hline
\end{tabular}


Microgels and nanogels capable of $\mathrm{pH}$ responsivity are widely used in cancer drug delivery systems. It is a well-known fact that the rate of glycolysis is higher in the hypoxic tumors than normal cells [105]. Due to increased energy demands, they convert pyruvate to lactate in order to replenish nicotinamide adenine (NAD ${ }^{+}$) reservoirs for the maintenance of glycolysis which in turn give rise to action of several enzymes and eventually result in a progressive decrease in the extracellular $\mathrm{pH}$ of the tumor microenvironment to approximately $\mathrm{pH} \sim 6.5$. Additionally, taking into account the low $\mathrm{pH}$ of endosomal and lysosomal compartments $\sim \mathrm{pH}$ 4.5-6.5, micro and nanovehicles able to change their volume or degrade in these $\mathrm{pH}$ ranges would have great potential for effective drug delivery to cancers cells. In this context, a variety of $\mathrm{pH}$ responsive particles are reported for drug delivery applications [106-108]. An exemplary study involves preparation of $\mathrm{HA}$ based $\mathrm{pH}$ responsive nanogels where methacrylated HA was crosslinked with an acid labile crosslinker 2,2-dimethacroyloxy1-ethoxypropane (DMAEP) and with a $\mathrm{pH}$ insensitive crosslinker as a control. Doxorubicin (DOX) was used a model drug in targeted delivery to Hep2G and MCF-7 cells. DOX-loaded HA nanogels were exhibited an ef- (a) a<smiles>C=CC(C)CCCC</smiles>
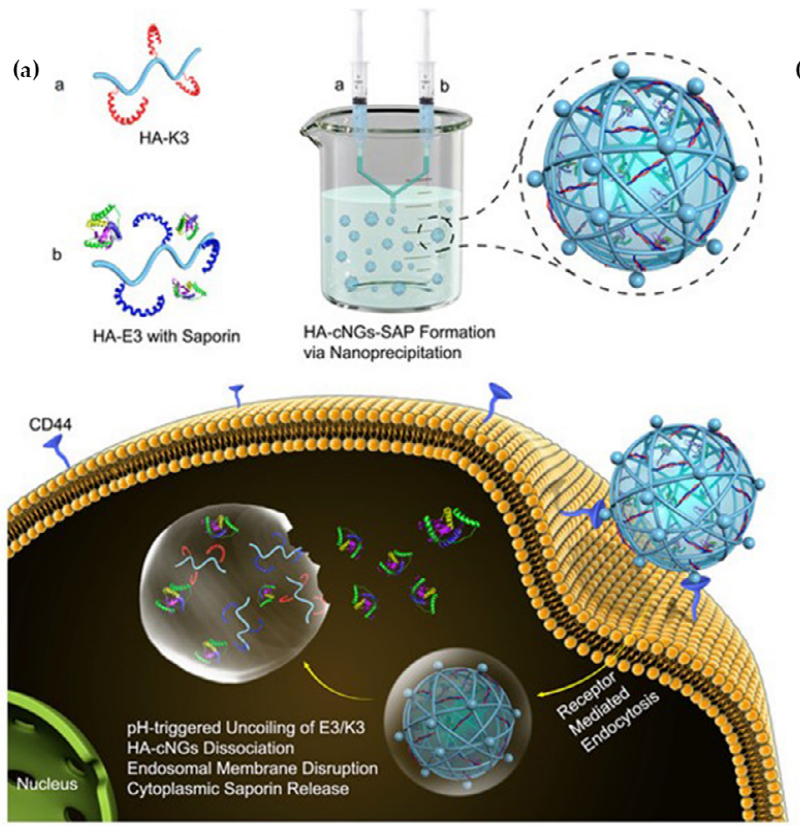
HA.CNGS-SAP Formation

(b)

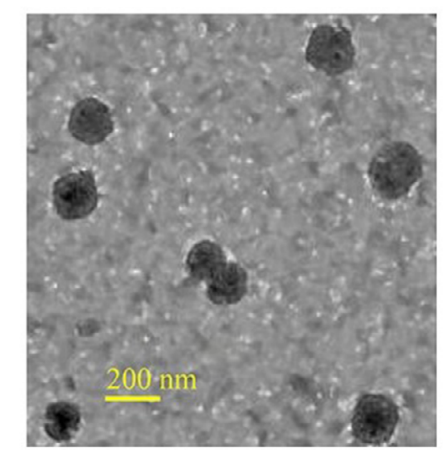

(c)

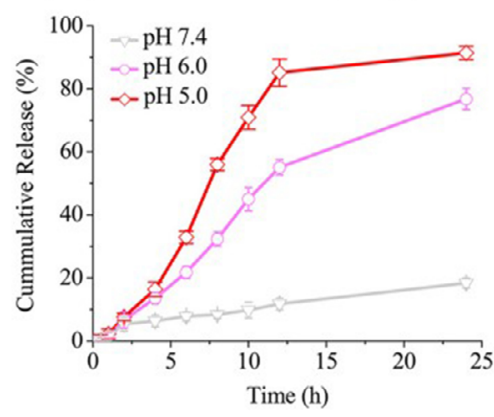

(d)

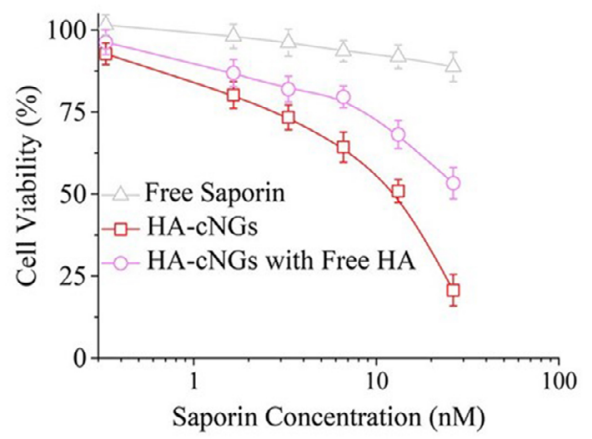

(e)

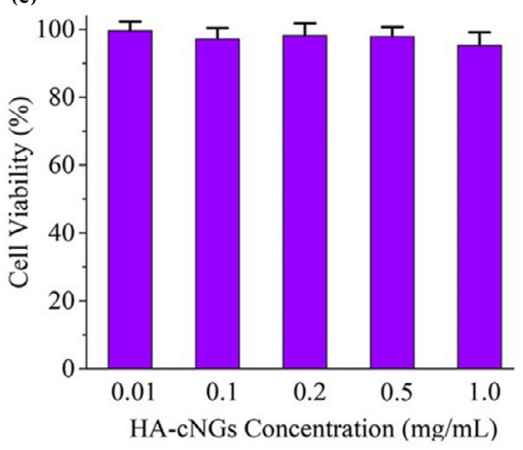

Figure 4.(a) Synthesis and (b) TEM images of coiled-coil peptide crosslinked HA-cNG particles, c) in vitro cytochrome $C$ release from HA-cNGs, and d-e) cytotoxicity of HA-cNG-SAP and blank nanogels to MCF-7 cells. Reproduced with the permission from ref [110], Copyright (C) 2017 American Chemical Society. 
ficient cellular uptake and degradation in comparison to $\mathrm{pH}$ insensitive $\mathrm{HA}$ nanogels. The in vivo study was performed on $\mathrm{H} 22$ tumor xenograft bearing mice and it is supportively found that $\mathrm{pH}$ sensitive HA nanogels could achieve better growth inhibition compared to $\mathrm{pH}$ insensitive HA nanogels and free DOX [109]. In another study performed by Ding et al. (2018), HA polysaccharides, were conjugated with GY(EIAALEK) ${ }_{3} \mathrm{GC}$ (E3) and GY(KIAALKE) ${ }_{3}$ GC (K3) peptides to prepare $\mathrm{pH}$ sensitive coiled-coil peptide crosslinked HA nanogels (HA-cNGs) by nanoprecipitation method as illustrated in Figure 4a) [110]. HA-cNGs shown in Figure 4b with $176 \mathrm{~nm}$ mean hydrodynamic sizes were loaded with cytochrome C (HA-cNG-CC) and in vitro protein release were studied at different $\mathrm{pH}$ environments. As seen from Figure $4 \mathrm{c}$ HA-cNG-CC nanogels showed $85 \%$ and $91 \%$ protein release at $\mathrm{pH} 5.0$ in 12 and 24 h, respectively, whereas at $\mathrm{pH} 6.0$ and 7.4 , gradually decreased protein release was observed as $76.8 \%$ and $18.4 \%$, respectively demonstrating their potential as low premature-release protein delivery systems. Cellular internalization of HACNG-CCs were investigated on MCF-7 human breast cancer cell lines and time dependent CD44-mediated internalization was confirmed.

Moreover, HA nanogels were further loaded with saporin, a membrane impermeable toxin. The obtained nanogels (HA-cNG-SAP) were tested for their internalization and growth inhibition efficacy on MCF-7 cells. As seen from Figure 4(d), the MTT assays of MCF-7 cells proved that HA-cNG-SAP nanogels had low half maximal inhibitory concentration $\left(\mathrm{IC}_{50}\right)$ of $12 \mathrm{nM}$. Pretreatment of the cells with free HA caused decrease in cell internalization of the particles hence less toxicity was attained, while free saporin showed the least cytotoxicity most likely due to impermeability to cell membrane. The flow cytometry analyses of HA-cNG-SAP nanogels revealed that they induced $19.2 \%$ apoptosis to MCF7 cells while blank nanogels did not show toxicity as seen in Figure $4 \mathrm{e}$. Recently, pH responsive biopolymerbased DNA nanogels were fabricated by host-guest interactions guided self-assembly of biotin conjugated branched DNAs (X-DNAs) and streptavidin for targeted delivery of DOX [111]. The DNA-protein hybrid (B-DNA) nanogels were further decorated with sgc8 aptamer DNAs to ensure targeting of tyrosine-protein kinase (PTK7) receptors overexpressed on HeLa and CRF-CEM cells. The prepared B-DNA nanogels in the range of 68 to $255 \mathrm{~nm}$ were achieved 93\% DOX encapsulation efficiency, selectively uptaken by HeLa and CRF-CEM can- cer cell lines and showed $\mathrm{pH}$ dependent drug release. In another study, biodegradable $\mathrm{p}$ (L-aspartic acid) nanogels were fabricated with $\mathrm{pH}$ responsive ability. The $\mathrm{p}$ (L-aspartic acid) based nanogels were synthesized by o/w emulsion crosslinking of poly[L-aspartic acid-g-(3diethylaminopropyl)]-b-PEG-maleimide $\quad[(p(L-A s p-g-$ DEAP)-b-PEG-Mal)] and poly(L-Asp-g-ethyl thiol)-b-PEG [(p(L-Asp-SH)-b-PEG))] block polymers [112]. The nanogels attained average particle size of about $125 \mathrm{~nm}$ and undergone to significant volume expansion when the $\mathrm{pH}$ was decreased from 7.4 to 5.0 by which the nanogels were envisaged to possess convenient utilization potential for lysosome targeted cancer therapy. P(LAsp) based drug-free nanogels showed more than 55\% toxicity against ovarian carcinoma SKOV3 cells most likely due to protonation of DEAP groups in the acidic cell microenvironment and low lysosomal $\mathrm{pH}$ whereas, once the lysosomes of the cells were neutralized, the blank nanogels did not induce toxicity. In vivo study of the DOX loaded nanogels on SKOV3 xenograft tumorbearing mice showed approximately two-fold treatment efficiency compared to free DOX and confirmed their potential as cancer drug delivery vehicles. Overall, these studies clearly indicate the efficiency of targeted and $\mathrm{pH}$ responsive natural biopolymers in cancer drug delivery.

Thermosensitive micro and nanogels are another type of versatile particles widely employed in stimuli responsive drug release applications [113-116]. Temperature sensitivity can be steadily imparted through micro and nanogels with various temperature responsive polymers that are included during particle synthesis are $\mathrm{p}(\mathrm{NIPAM})$ and poly(N-vinyl caprolactam) ( $(\mathrm{NVCL}))$ as the most commonly used thermosensitive polymers $[116,117]$. For example, lower critical solution temperature (LCST) of $p$ (NIPAM) lies approximately at $32^{\circ} \mathrm{C}$, below this temperature $\mathrm{p}$ (NIPAM) polymers are well hydrated in water via hydrogen bonding due to increased hydrophilicity of polymers whereas above LCST, the hydrophobicity of the polymer increases further where the polymer undergoes a volume phase transition and shrinks because of the decreased polymer-solvent interactions (i.e. hydrogen bonding) and increased polymer-polymer interactions which are mostly hydrophobic $[118,119]$. Drug release behaviors of thermosensitive microgels and nanogels can be controlled by locally increasing the temperature of the target site e.g., for tumors hyperthermia can be induced to trigger release of the therapeutic cargo [120]. Rejinold et 
al. (2011) reported preparation of $\mathrm{p}(\mathrm{NVCL})$ grafted $\mathrm{CHI}$ (CHI-p(NVCL)) particles by ionic crosslinking technique [121]. LCST of the polymer was proven to be tunable depending on the feed concentrations of precursors and determined to be $38^{\circ} \mathrm{C}$ at $1: 9 \mathrm{CHI}: \mathrm{p}(\mathrm{NVCL})$ ratio. The cancer drug 5-Fluorouracil (5-FU) was encapsulated within the particles in the course of particle formation. In vitro drug release experiments were performed at above and below the LCST of the particles. In three days, only 5\% 5-FU release was observed at below LCST whereas 40\% 5-FU release was achieved from the particles above the LCST. 5-FU loaded CHI-p(NVCL) showed concentration dependent cytotoxicity to PC3, MCF-7 and $\mathrm{KB}$ cells while blank $\mathrm{CHI}-\mathrm{p}(\mathrm{NVCL})$ particles showed negligible toxicity. As shown in the study, tunability of the LCST of the particles could provide remarkable potential for hypothermia induced drug delivery. Another study demonstrates synthesis of $\mathrm{k}$-Carrageenan nanogels by reverse micelle microemulsion polymerization combined with temperature incited gelation process [122]. Potassium ions from $\mathrm{KCl}$ were used as crosslinker for nanogel formation and the size of the nanogels were shown to be easily tunable by changing the biopolymer concentration while the surfactant ratio was kept constant. Ultimately nanogels with less than $100 \mathrm{~nm}$ sizes were obtained. $\mathrm{k}$-Carrageenan nanogels were shown to exhibit gel-to sol transition from 20 to $45^{\circ} \mathrm{C}$ and intended for their application potentials as drug delivery devices. Methylene blue was a chosen as a model cationic payload, loaded to k-carrageenan nanogels by post synthesis impregnation method. Nanogels were observed to exhibit temperature dependent drug release at 25 , 37 , and $45^{\circ} \mathrm{C}$ showing their potential as temperature sensitive carriers for cationic drugs. Biopolymers such as $\mathrm{CHI}, \mathrm{HA}$, dextran, caboxymethylcellulose and so on can be coupled with thermoresponsive moieties for natural and safe thermo-triggered drug delivery applications [113,116,123,124]. Stefanello et al. (2014) reported synthesis of thermoresponsive HA nanogels for macrophage drug delivery [125]. In their study, HA molecules were conjugated with oligo(ethylene glycol)based thermoresponsive polymers via thiol-ene chemistry, consequently, self-assembled thermoresponsive $\mathrm{HA}$ nanogels ranged from 150 to $214 \mathrm{~nm}$ were successfully demonstrated the delivery of a hydrophobic dye to RAW264.7 macrophages in vitro, and also in vivo through mice by intravenous injection. Thermoresponsive HA nanogels were shown to be phagocytized by circulating macrophages of mice in 13 minutes. In another study conducted by Sahiner et al. (2011), divinyl sulfone crosslinked HA microgels were synthesized using w/o reverse microemulsion polymerization and are coupled with cysteamine molecules upon periodate treatment [126]. Thiol functionalized HA microgels were conjugated with $\mathrm{p}$ (NIPAM) to introduce temperature sensitivity. Temperature sensitive HA microgels were tested for in vitro release of sulfamethoxazole as a model drug and showed enhanced drug release in comparison to unmodified $\mathrm{HA}$ microgels at $37^{\circ} \mathrm{C}$. The $\mathrm{HA}$ microgels were also prepared as magnetic field responsive upon encapsulation of magnetic $\mathrm{Fe}_{3} \mathrm{O}_{4}$ nanoparticles during particle synthesis. Beside drug delivery, thermo responsive microgels and nanogels can also used in separation [127], biosensor [128], and tissue engineering applications [129].

Magnetic field responsive materials attain particular attention and utilization for site directed vectoring and delivery of therapeutic agents especially as cell ordering, tissue assembly, and scaffolding materials in tissue engineering applications as well as delivery of growth factors imaging and drug delivery to solid tumors in cancer treatment [130-134]. Biopolymers owing to their biodegradable biocompatible and safe characteristics have gained widespread utilization in tissue engineering applications [135-138]. Fan et al. (2014) reported preparation of a biopolymer based magnetic nanogels of $109.4 \mathrm{~nm}$ by coupling heparin and $\mathrm{CHI}$ with adenine and thymine nucleobases and subsequent encapsulation of $\mathrm{Fe}_{3} \mathrm{O}_{4}$ magnetic nanoparticles in self-assembled nanogels [139]. In vitro release of bone morphogenetic protein 2 (BMP-2) as growth factor in physiological conditions and their cytotoxicity to MG-63 bone osteosarcoma cells were investigated. Innate ability of heparin in the nanogel composition promoted high protein loading efficiency and promoted proliferation of MG-63 cell along with magnetic field controlled sustained release.

Beside single targeting and stimulus directed control over the release behaviors of micro nanogels, development of particles with combined multiple targeting and stimuli responsivity gave rise to emergence of multifunctional captivating materials that provide more stable and controlled delivery to target sites of interest and achieve elongated systemic circulation half-lives. A recent example of multiresponsive and targeted nanogel preparation based on biopolymer coating was reported by Zhang et al. (2017), and scheme of the nanogels synthesis was shown in Figure 5a [140]. In their study, glycosyl functionalized nanogels 
(a)
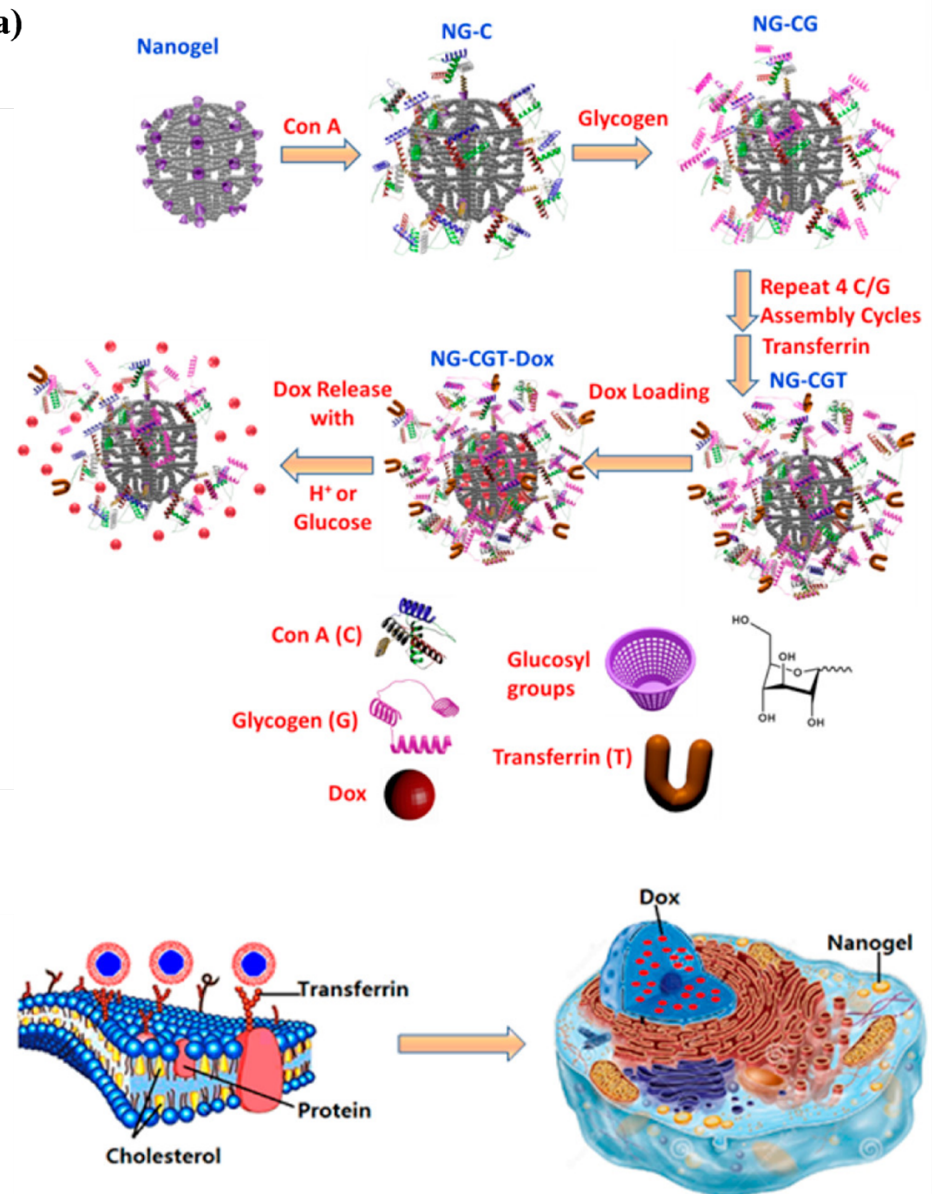

(b)

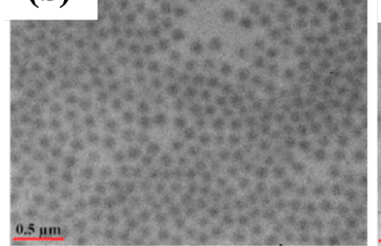

(e)
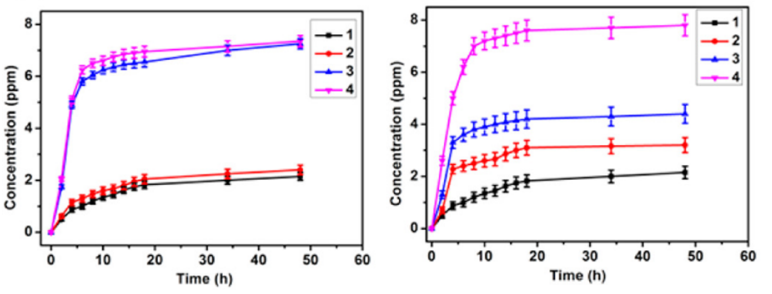

(c)

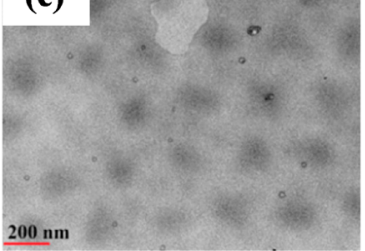

(f)

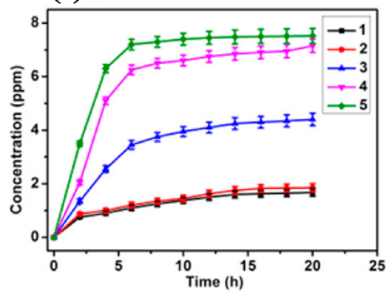

(g)

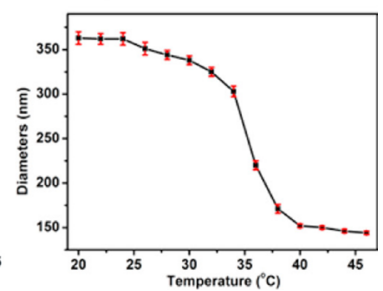

Figure 5. (a) Schematic illustration of synthesis of NG-CGT-DOX nanogels, and TEM images of (b) NG and (c) NG-CGT nanogels, and "in vitro drug release profiles of free Dox (d) triggered at different $\mathrm{pHs}(1: \mathrm{pH} 7.4 ; 2: \mathrm{pH} 6 ; 3: \mathrm{pH} 5 ; 4: \mathrm{pH} 4)$, (e) triggered by various glucose concentrations (1:400 ppm, 2:700 ppm, 3:1000 ppm, 4:1300 ppm) at pH 7.4, and (f) triggered by different temperatures (1: pH 7.4 at $25^{\circ} \mathrm{C} ; 2: \mathrm{pH} 7.4$ at $37^{\circ} \mathrm{C} ; 3: \mathrm{pH} 4$ at $25^{\circ} \mathrm{C} ; 4: \mathrm{pH} 4$ at $37^{\circ} \mathrm{C} ; 5: \mathrm{pH} 4$ at $\left.45^{\circ} \mathrm{C}\right)$, and $(\mathrm{g})$ the change in NG-CGT particle diameters as a function of temperature by DLS measurements". Reproduced with the permission from ref [140], Copyright (C 2018 American Chemical Society. 
(NGs) prepared by polymerization of $\mathrm{p}(\mathrm{NIPAM}), \mathrm{N}, \mathrm{N}^{\prime}-$ methylenebis(acrylamide) (BIS), and glycosyl methacrylate units via free radical precipitation polymerization. The obtained glucosyl functionalized thermoresponsive NGs were subjected to repeated cycles of sequential coating with Concanavalin A (Con A, a well-known glucose binding lectin) and the glycogen molecules exploiting the sugar-lectin binging affinity. Ability of Con A to change its conformation from tetramer to dimeric units as well as its affinity for glucose were exploited to give nanogels $\mathrm{pH}$, and glucose responsivity. The nanogels were further exposed to biocoating with transferrin molecules to impart target specificity consequently, as shown in Figure 5b nanogels of approximately $180 \mathrm{~nm}$ sizes were produced. Ultimately, the obtained nanogels (NG-CGTs) endowed with glucose, $\mathrm{pH}$, and temperature responsivity and transferrin targeting as shown in Figure $5 \mathrm{c}$ were loaded with DOX (NG-CGT-DOX) and then tested for their in vitro drug release. The in vitro DOX release from NG-CGT-DOX nanogels were quantified in different $\mathrm{pH}$, temperature, and glucose concentrations. Their respective drug release profiles along with temperature dependent swelling capacities were shown in Figure $5 \mathrm{~d}$-g. The NG-CGT-DOX nanogels released $1.8 \mathrm{ppm}$ DOX in 20h at $\mathrm{pH} 7.4$ which was increased to $2.1 \mathrm{ppm}$ after 2 days. At pH 5.0, 6.5 ppm DOX release was determined after $20 \mathrm{~h}$, on the other hand at $\mathrm{pH} 4$, the released amount of DOX was increased to $7.2 \mathrm{ppm}$ that clearly demonstrated $\mathrm{pH}$-dependent release of DOX from the nanogels. Moreover, release studies performed at different glucose concentrations from 400 to $1200 \mathrm{ppm}$, and respectively 1.8 to 7.6 DOX release was observed. The authors anticipated that glucose dependent DOX release might be due to weakening of the nanogel coat and increase in the network porosity as a result of hydrogen bonding between Con A and glucose in the release medium. For the temperature dependent drug release increasing the temperature from $25^{\circ} \mathrm{C}$ to $37^{\circ} \mathrm{C}$ at $\mathrm{pH} 7.4$ did not cause a significant acceleration in DOX release however, when the same temperature treatment combined with the $\mathrm{pH} 4.0 \mathrm{pH} 5.0$ conditions or 1200 ppm glucose solution, a significant acceleration was observed on the DOX release which was attributed to partial degradation and porosity increase of the biopolymer coating.

TfR mediated internalization of NG-CGT-DOX nanogels were confirmed on Hep2G cancer cell lines and the nanogels were found to maintain their stability for two months at $-20^{\circ} \mathrm{C}$. Based on these results, triple stimuli responsive and TfR targeted NG-CGT nanogels prominently demonstrated the efficiency of biopolymer based modification over the control of drug release for targeted drug delivery applications in nanomaterial based cancer therapy.

A number of combinations of multiresponsive and targeted micro/nano carriers have been reported for different purpose $[102,141]$. For example, $\mathrm{pH}$, and reduction sensitive and targeted micro/nano vehicles have been prepared where they are particularly useful for cancer drug delivery due to the fact that both intracellular concentration of glutathione and $\mathrm{pH}$ favor the degradation of the carriers and consequent release of their payloads [142-145]. Likewise, temperature and redox dual responsive zwitterionic nanogels loaded with a near infrared (NIR) dye have been fabricated. In addition to their glutathione degradability, NIR light-induced tumor accumulation, enhanced penetration, cellular uptake, and size reduction of nanogels were reported with prolonged circulation half-lives [146]. Alternatively, dual stimuli responsive nanovehicles containing redox and irradiation cleavable groups (e.g. disulfide and onitrobenzyl methyl ester groups) can enable efficient control over the rate of drug release either slowly by intracellular reduction or burst release upon UV light exposure [147]. Another combination of multi-stimuli responsivity can accommodate particles selective drug release where hydrophobic drugs were encapsulated in lipophilic core of the nanogels via hydrophobic interactions while hydrophilic drugs were linked to $\mathrm{pH}$, temperature, and redox responsive polymer backbone by redox sensitive disulfide bonds [148]. Nanogels also contained photocleavable crosslinkers in their composition. While this is the case, hydrophobic drugs were shown to be released in response to UV light, $\mathrm{pH}$, or temperature by causing a volume change on the nanogels that would not affect the release of covalently bonded hydrophilic drugs. On the other hand, release of the hydrophilic drugs can be triggered in response to redox environment (e.g. dithiothreitol).

\section{CONCLUSION}

Microgels and nanogels hold unprecedented potentials in biomedical applications due to their unique properties e.g., high-water content, biocompatibility, and ease of manipulation in terms of size charge, functional groups, and biodegradability and stimuli sensitivity. Furthermore, microgels and nanogels can be equipped 
with responsive moieties as well as specific targeting ligands which give them additional versatility and control over their release behaviors. Besides, addition of hydrophilic polymers on micro/nanogel matrix can help balance their in vivo residence times. Although PEG accommodates successful avoidance from phagocytosis, some studies have reported its inhibition/interference on cellular uptake and endosomal escape of micro/nano carriers which is rather known as "PEG dilemma" [84]. In this context, alternative shielding strategies such as cleavable PEG systems, use of biopolymers or membrane coating has been proposed $[7,85,88,91]$. Additionally, multi stimuli responsive and multiple targeting micro- and nano-vehicles have been reported to cope with complex and stringent barriers of in vivo environment. However, these raises laborious preparation and batch variations along with the increased cost of the formulations which in turn appears to be one of the critical limiting factors that can impede clinical translation of these particle systems. Another problem for micro/ nano carriers to enter clinical use is their variable mode of action or inadequacy of the laboratory experiments to model in vivo 3D environment of the tumors as the cell cultures or xenograft animal models may follow different modes and kinetics of progression and also interindividual variability of many diseases in real human subjects make the progress rather more challenging. As a conclusion, development of micro/nanogels should be conducted in more united and synchronous fashion with in vitro, in vivo, and in silico arms of science and industry as it is intended with a project named Digital Human for Drug Development (DHD2) in recent years and is under development aiming to model and predict in vivo actions of drugs in human and mice models $[84,149]$.

\section{References}

1. H. Staudinger, Über polymerisation, Ber. Dtsch. Chem. Ges. (A B Ser.), 53 (1920) 1073-1085.

2. R. Mülhaupt, Hermann staudinger and the origin of macromolecular chemistry, Angew. Chem., Int. Ed., 43 (2004) 1054-1063.

3. H. Ringsdorf, Hermann staudinger and the future of polymer research jubilees-beloved occasions for cultural piety, Angew. Chem., Int. Ed., 43 (2004) 1064-1076.

4. M.H. Kim, G. Choi, A. Elzatahry, A. Vinu, Y.B. Choy, J.H. Choy, Review of clay-drug hybrid materials for biomedical applications: Administration routes, Clays Clay Miner., 64 (2016) 115-130.
5. C. Cha, S.R.Shin, N. Annabi, M.R. Dokmeci, A. Khademhosseini, Carbon-based nanomaterials: Multifunctional materials for biomedical engineering, ACS Nano, 7 (2013) 2891-2897.

6. M.C. Tan, G.M. Chow, L. Ren, Q. Zhang, Inorganic nanoparticles for biomedical applications, Nanosci. Biomed., Springer Berlin Heidelberg, Berlin, Heidelberg, vol? 2009 272-289.

7. H. Hatakeyama, H. Akita, H. Harashima, A multifunctional envelope type nano device (MEND) for gene delivery to tumours based on the EPR effect: A strategy for overcoming the PEG dilemma, Adv. Drug Delivery Rev., 63 (2011) 152160.

8. Y. Panahi, M. Farshbaf, M. Mohammadhosseini, M. Mirahadi, R. Khalilov, S. Saghfi, A. Akbarzadeh, Recent advances on liposomal nanoparticles: synthesis, characterization and biomedical applications, Artif. Cells Nanomed. Biotechnol., 45 (2017) 788-799.

9. L. Nyström, A.A. Strömstedt, A. Schmidtchen, M. Malmsten, Peptide-loaded microgels as antimicrobial and antiinflammatory surface coatings, Biomacromolecules, 19 (2018) 3456-3466.

10. R. Nordström, L. Nyström, O.C.J. Andrén, M. Malkoch, A. Umerska, M. Davoudi, A. Schmidtchen, M. Malmsten, Membrane interactions of microgels as carriers of antimicrobial peptides, J. Colloid Inter. Sci., 513 (2018) 141-150.

11. K.H. Bae, H.J. Chung, T.G. Park, Nanomaterials for cancer therapy and imaging, Mol. Cells, 31 (2011) 295-302.

12. H. Staudinger, E. Husemann, Über hochpolymere verbindungen, 116. Mitteil.: Über das begrenzt quellbare poly-styrol, Ber. Dtsch. Chem. Ges. (A B Ser.), 68 (1935) 1618-1634.

13. W. Funke, O. Okay, B. Joos-Müller, Microgels-intramolecularly crossünked macromolecules with a globular structure, in: microencapsul. microgels iniferters, Springer Berlin Heidelberg, Berlin, Heidelberg, n.d.: pp. 139-234.

14. W.O. Baker, Microgel, a new macromolecule, Ind. Eng. Chem. Res., 41 (1949) 511-520.

15. M. Tsintou, C. Wang, K. Dalamagkas, D. Weng, Y.-N. Zhang, W. Niu, Nanogels for biomedical applications: Drug delivery, imaging, tissue engineering, and biosensors, in: Nanobiomaterials Sci. Dev. Eval., Elsevier, 2017: pp. 87-124.

16. G. Agrawal, R. Agrawal, Functional microgels: Recent advances in their biomedical applications, Small., 14 (2018) 1801724.

17. Z. Shen, A. Mellati, J. Bi, H. Zhang, S. Dai, A thermally responsive cationic nanogel-based platform for threedimensional cell culture and recovery, RSC Adv., 4 (2014) 29146.

18. A.C. Daly, L. Riley, T. Segura, J.A. Burdick, Hydrogel microparticles for biomedical applications, Nat. Rev. Mater., 5 (2020) 20-43.

19. S.S. Suner, M. Şahiner, S.B. Şengel, D.J. Rees, W.F. Reed, N. Şahiner, Responsive biopolymer-based microgels/nanogels for drug delivery applications, in: Stimuli Responsive Polym. Nanocarriers Drug Deliv. Appl. Vol. 1, Elsevier, 2018: pp. 453500.

20. Narain, S. Asawa, V. Chhabria, Y. Patil-Sen, Cell membrane coated nanoparticles: next-generation therapeutics, Nanomedicine, 12 (2017) 2677-2692.

21. J.K. Oh, D.I. Lee, J.M. Park, Biopolymer-based microgels/ nanogels for drug delivery applications, Prog. Polym. Sci., 34 (2009) 1261-1282.

22. K. Akiyoshi, S. Deguchi, N. Moriguchi, S. Yamaguchi, J. Sunamoto, Self-aggregates of hydrophobized polysaccharides in water. Formation and characteristics of nanoparticles, Macromolecules, 26 (1993) 3062-3068. 
23. E. Mueller, R.J. Alsop, A. Scotti, M. Bleuel, M.C. Rheinstädter W. Richtering, T. Hoare, Dynamically cross-linked selfassembled thermoresponsive microgels with homogeneous internal structures, Langmuir, 34 (2018) 1601-1612.

24. J. Varshosaz, S. Taymouri, E. Ghassami, Supramolecular selfassembled nanogels a new platform for anticancer drug delivery, Curr. Pharm. Des., 23 (2017) 5242-5260.

25. J.M. Myrick, V.K. Vendra, S. Krishnan, Self-assembled polysaccharide nanostructures for controlled-release applications, Nanotechnol. Rev. 3 (2014) page number?.

26. T. Zhang, R. Yang, S. Yang, J. Guan, D. Zhang, Y. Ma, H. Liu, Research progress of self-assembled nanogel and hybrid hydrogel systems based on pullulan derivatives, Drug Delivery, 25 (2018) 278-292.

27. T.V. Tran, T.H.D. Phuong, N.Q. Tran, C.K. Nguyen, D.H Nguyen, Polymeric chitosan based nanogels as a potential platform for dual targeted drug delivery in cancer therapy, Int. J. Nanotechnol., 15 (2018) 188.

28. P. Pereira, S.S. Pedrosa, A. Correia, C.F. Lima, M.P. Olmedo, Á. González-Fernández, M. Vilanova, F.M. Gama, Biocompatibility of a self-assembled glycol chitosan nanogel, Toxicol. In Vitro, 29 (2015) 638-646.

29. L.C. Cheng, Y. Jiang, Y. Xie, L.L. Qiu, Q. Yang, H.Y. Lu, Novel amphiphilic folic acid-cholesterol-chitosan micelles for paclitaxel delivery, Oncotarget, 8 (2017) 3315-3326.

30. L.M. Bravo-Anaya, J.F.A. Soltero, M. Rinaudo, DNA/chitosan electrostatic complex, Int. J. Biol. Macromol., 88 (2016) 345 353.

31. V. Chavasit, C. Kienzle-Sterzer, J. Antonio Torres, Formation and characterization of an insoluble polyelectrolyte complex: Chitosan-polyacrylic acid, Polym. Bull., 19 (1988) 223-230.

32. A.M. Alsharabasy, S.A. Moghannem, W.N. El-Mazny, Physical preparation of alginate/chitosan polyelectrolyte complexes for biomedical applications, J. Biomater. Appl., 30 (2016) 1071-1079.

33. T. Dai, S. Zhou, C. Yin, S. Li, W. Cao, W. Liu, K. Sun, H. Dou, Y. Cao, G. Zhou, Dextran-based fluorescent nanoprobes for sentinel lymph node mapping, Biomaterials, 35 (2014) 82278235.

34. S. Zhou, X. Min, H. Dou, K. Sun, C.Y. Chen, C.T. Chen, Z. Zhang, Y. Jin, Z. Shen, Facile fabrication of dextran-based fluorescent nanogels as potential glucose sensors, Chem. Comm., 49 (2013) 9473.

35. O. Mezghrani, Y. Tang, X. Ke, Y. Chen, D. Hu, J. Tu, L. Zhao, N. Bourkaib, Hepatocellular carcinoma dually-targeted nanoparticles for reduction triggered intracellular delivery of doxorubicin, Int. J. Pharm., 478 (2015) 553-568.

36. S. Trombino, C. Servidio, F. Curcio, R. Cassano, Strategies for hyaluronic acid-based hydrogel design in drug delivery, Pharmaceutics, 11 (2019) 407

37. Q. Feng, Q. Li, H. Wen, J. Chen, M. Liang, H. Huang, D. Lan $H$. Dong, X. Cao, Injection and self-assembly of bioinspired stem cell-laden gelatin/hyaluronic acid hybrid microgels promote cartilage repair in vivo, Adv. Funct. Mater., 29 (2019) 1906690.

38. G. Huang, H. Huang, Application of hyaluronic acid as carriers in drug delivery, Drug Delivery, 25 (2018) 766-772.

39. Y.C. Kuo, C.H. Hsueh, Neuronal production from induced pluripotent stem cells in self-assembled collagen-hyaluronic acid-alginate microgel scaffolds with grafted GRGDSP/ Ln5-P4, Mater. Sci. Eng., C, 76 (2017) 760-774.

40. K. Zhao, D. Li, W. Xu, J. Ding, W. Jiang, M. Li, C. Wang, X. Chen, Targeted hydroxyethyl starch prodrug for inhibiting the growth and metastasis of prostate cancer, Biomaterials, 116 (2017) 82-94.
41. M. Kohri, Y. Nannichi, T. Taniguchi, K. Kishikawa, Biomimetic non-iridescent structural color materials from polydopamine black particles that mimic melanin granules, J. Mater. Chem. C, 3 (2015) 720-724

42. W. Li, M. Yalcin, Q. Lin, M.-S.M. Ardawi, S.A. Mousa, Selfassembly of green tea catechin derivatives in nanoparticles for oral lycopene delivery, J. Controlled Release, 248 (2017) 117-124.

43. J.E. Chung, S. Tan, S.J. Gao, N. Yongvongsoontorn, S.H. Kim, J.H. Lee, H.S. Choi, H. Yano, L. Zhuo, M. Kurisawa, J.Y. Ying, Self-assembled micellar nanocomplexes comprising green tea catechin derivatives and protein drugs for cancer therapy, Nat. Nanotechnol., 9 (2014) 907-912.

44. Y.C. Chen, S.H. Yu, G.J. Tsai, D.W. Tang, F.L. Mi, Y.P. Peng, Novel technology for the preparation of self-assembled catechin/gelatin nanoparticles and their characterization, J. Agric. Food Chem., 58 (2010) 6728-6734.

45. Purwada, Y.F. Tian, W. Huang, K.M. Rohrbach, S. Deol, A. August, A. Singh, Self-assembly protein nanogels for safer cancer immunotherapy, Adv. Healthcare Mater., 5 (2016) 1413-1419.

46. T. Nishimura, A. Yamada, K. Umezaki, S. Sawada, S. Mukai, Y. Sasaki, K. Akiyoshi, Self-assembled polypeptide nanogels with enzymatically transformable surface as a small interfering RNA delivery platform, Biomacromolecules, 18 (2017) 3913-3923.

47. W.T. Arab, A.M. Niyas, K. Seferji, H.H. Susapto, C.A.E. Hauser, Evaluation of peptide nanogels for accelerated wound healing in normal micropigs, Front. Nanosci. Nanotechnol. 4 (2018).

48. P. Chakraborty, E. Gazit, Amino acid based self-assembled nanostructures: Complex structures from remarkably simple building blocks, ChemNanoMat, 4 (2018) 730-740.

49. H.V.P. Thelu, S.K. Albert, M. Golla, N. Krishnan, D. Ram, S.M. Srinivasula, R. Varghese, Size controllable DNA nanogels from the self-assembly of DNA nanostructures through multivalent host-guest interactions, Nanoscale, 10 (2018) 222-230.

50. H. Xue, F. Ding, J. Zhang, Y. Guo, X. Gao, J. Feng, X. Zhu, C. Zhang, DNA tetrahedron-based nanogels for siRNA delivery and gene silencing, Chem. Commun., 55 (2019) 4222-4225.

51. N. Sanson, J. Rieger, Synthesis of nanogels/microgels by conventional and controlled radical crosslinking copolymerization, Polym. Chem., 1 (2010) 965.

52. Y. Bin Hamzah, S. Hashim, W.A.W.A. Rahman, Synthesis of polymeric nano/microgels: A review, J. Polym. Res., 24 (2017) 134

53. M. Matusiak, S. Kadlubowski, J.M. Rosiak, Nanogels synthesized by radiation-induced intramolecular crosslinking of water-soluble polymers, Radiat. Phys. Chem., 169 (2020) 108099.

54. M. Matusiak, S. Kadlubowski, P. Ulanski, Radiation-induced synthesis of poly(acrylic acid) nanogels, Radiat. Phys. Chem., 142 (2018) 125-129.

55. Adrian Alejandro Ges Naranjo, HerlysViltres Cobas, Danaydis Fonseca Rogdriguez, Manuel Rapado Paneque, Yuri Aguilera Corrales, Radiation-induced synthesis of polyvinylpyrrolidone (PVP) nanogels, J. Phys. Sci. Appl. 6 (2016) page number?

56. K. Raghupathi, S.J. Eron, F. Anson, J.A. Hardy, S. Thayumanavan, Utilizing inverse emulsion polymerization to generate responsive nanogels for cytosolic protein delivery, Mol. Pharm., 14 (2017) 4515-4524. 
57. S.F. Medeiros, A.M. Santos, H. Fessi, A. Elaissari, Synthesis of biocompatible and thermally sensitive poly $(\mathrm{N}$ vinylcaprolactam) nanogels via inverse miniemulsion polymerization: Effect of the surfactant concentration, J. Polym. Sci., Part A: Polym. Chem., 48 (2010) 3932-3941.

58. C. Daubresse, C. Grandfils, R. Jerome, P. Teyssie, Enzyme immobilization in nanoparticles produced by inverse microemulsion polymerization, J. Colloid Inter. Sci., 168 (1994) 222-229.

59. T. Madan, N. Munshi, T.K. De, A. Maitra, P. Usha Sarma, S.S. Aggarwal, Biodegradable nanoparticles as a sustained release system for the antigens/allergens of Aspergillus fumigatus: Preparation and characterisation, Int. J. Pharm., 159 (1997) 135-147.

60. D.J. Bharali, S.K. Sahoo, S. Mozumdar, A. Maitra, Cross-linked polyvinylpyrrolidone nanoparticles: A potential carrier for hydrophilic drugs, J. Colloid Inter. Sci., 258 (2003) 415-423.

61. N. Şahiner, S. Demirci, Can PEI microgels become biocompatible upon betainization?, Mater. Sci. Eng., C., 77 (2017) 642-648.

62. T. Hoare, S. Young, M.W. Lawlor, D.S. Kohane, Thermoresponsive nanogels for prolonged duration local anesthesia, Acta Biomater., 8 (2012) 3596-3605.

63. N. Şahiner, S. Sağbaş, M. Türk, Poly(sucrose) micro particles preparation and their use as biomaterials, Int. J. Biol. Macromol., 66 (2014) 236-244.

64. M. Can, R.S. Ayyala, N. Şahiner, Crosslinked poly(Lactose) microgels and nanogels for biomedical applications, J. Colloid Inter. Sci., 553 (2019) 805-812.

65. M.A. Pujana, L. Pérez-Álvarez, L.C. Cesteros Iturbe, I. Katime, Water dispersible $\mathrm{pH}$-responsive chitosan nanogels modified with biocompatible crosslinking-agents, Polymer, 53 (2012) 3107-3116

66. N. Şahiner, S. Sağbaş, H. Yoshida, L.A. Lyon, Synthesis and properties of inulin based microgels, Colloids Inter. Sci. Commun., 2 (2014) 15-18.

67. H. Su, Q. Jia, S. Shan, Synthesis and characterization of Schiff base contained dextran microgels in water-in-oil inverse microemulsion, Carbohydr. Polym., 152 (2016) 156-162.

68. E. Jooybar, M.J. Abdekhodaie, P.J. Dijkstra, Synthesis of hyaluronic acid-tyramine microgels for sustained protein release, in: 2018 25th Natl. 3rd Int. Iran. Conf. Biomed. Eng. IEEE, 2018: pp. 1-5

69. N. Şahiner, S.S. Suner, R.S. Ayyala, Mesoporous, degradable hyaluronic acid microparticles for sustainable drug delivery application, Colloids Surf., B, 177 (2019) 284-293.

70. S. Bütün, F.G. Ince, H. Erduğan, N. Şahiner, One-step fabrication of biocompatible carboxymethyl cellulose polymeric particles for drug delivery systems, Carbohydr Polym., 86 (2011) 636-643.

71. Y. Ke, G.S. Liu, J.H. Wang, W. Xue, C. Du, G. Wu, Preparation of carboxymethyl cellulose based microgels for cell encapsulation, eXPRESS Polym. Lett., 8 (2014) 841-849.

72. S.S. Suner, N. Sahiner, Biocompatible macro, micro and nano scale guar gum hydrogels and their protein absorption capacity, J. Macromol. Sci. Part A. (2020) 1-9. https://doi.or $\mathrm{g} / 10.1080 / 10601325.2020 .1787844$.

73. N. Şahiner, S. Sağbaş, N. Aktaş, C. Silan, Inherently antioxidant and antimicrobial tannic acid release from poly(tannic acid) nanoparticles with controllable degradability, Colloids Surf., B, 142 (2016) 334-343.

74. M. Şahiner, N. Şahiner, S. Sağbaş, M.L. Fullerton, D.A. Blake, Fabrication of biodegradable poly(naringin) particles with antioxidant activity and low toxicity, ACS Omega, 3 (2018) 17359-17367.
75. N. Şahiner, One step poly(quercetin) particle preparation as biocolloid and its characterization, Colloids Surf., A, 452 (2014) 173-180.

76. N. Şahiner, One step poly(rutin) particle preparation as biocolloid and its characterization, Mater. Sci. Eng., C, 44 (2014) 9-16.

77. N. Wang, X. Cheng, N. Li, H. Wang, H. Chen, Nanocarriers and their loading strategies, Adv. Healthcare Mater., 8 (2019) 1801002

78. J.M. Morachis, E.A. Mahmoud, A. Almutairi, Physical and chemical strategies for therapeutic delivery by using polymeric nanoparticles, Pharmacol. Rev., 64 (2012) 505519.

79. N. Şahiner, S. Sağbaş, S. Yılmaz, Microgels derived from different forms of carrageenans, kappa, iota, and lambda for biomedical applications, MRS Adv., 2 (2017) 2521-2527.

80. G. Pasut, F.M. Veronese, Polymer-drug conjugation, recent achievements and general strategies, Prog. Polym. Sci., 32 (2007) 933-961.

81. Y.R. Choi, H. J. Kim, G.Y. Ahn, M.J. Lee, J.R. Park, D.R. Jun, T.K. Ryu, J.W. Park, E. Shin, S.W. Choi, Fabrication of dihydroxyflavoneconjugated hyaluronic acid nanogels for targeted antitumoral effect, Colloids Surf., B, 171 (2018) 690-697.

82. J.P. Nam, S.C. Park, T.H. Kim, J.Y. Jang, C. Choi, M.K. Jang, J.W. Nah, Encapsulation of paclitaxel into lauric acid-O-carboxymethyl chitosan-transferrin micelles for hydrophobic drug delivery and site-specific targeted delivery, Int. J. Pharm., 457 (2013) 124-135.

83. E. Mauri, G. Perale, F. Rossi, Nanogel functionalization: A versatile approach to meet the challenges of drug and gene delivery, ACS Appl. Nano Mater., 1 (2018) 6525-6541.

84. N.H. Abd Ellah, S.A. Abouelmagd, Surface functionalization of polymeric nanoparticles for tumor drug delivery: Approaches and challenges, Expert Opin. Drug Deliv., 14 (2017) 201-214.

85. Z. Amoozgar, Y. Yeo, Recent advances in stealth coating of nanoparticle drug delivery systems, Wiley Interdiscip. Rev. Nanomed. Nanobiotechnol., 4 (2012) 219-233.

86. M. Noga, D. Edinger, W. Rödl, E. Wagner, G. Winter, A. Besheer, Controlled shielding and deshielding of gene delivery polyplexes using hydroxyethyl starch (HES) and alpha-amylase, J. Controlled Release, 159 (2012) 92-103.

87. Z. Amoozgar, J. Park, Q. Lin, Y. Yeo, Low molecular-weight chitosan as a ph-sensitive stealth coating for tumor-specific drug delivery, Mol. Pharm., 9 (2012) 1262-1270.

88. L. Cui, Q. Lin, C.S. Jin, W. Jiang, H. Huang, L. Ding, N. Muhanna, J.C. Irish, F. Wang, J. Chen, G. Zheng, A PEGylation-free biomimetic porphyrin nanoplatform for personalized cancer theranostics, ACS Nano, 9 (2015) 4484-4495.

89. P.L. Rodriguez, T. Harada, D.A. Christian, D.A. Pantano, R.K. Tsai, D.E. Discher, Minimal "self" peptides that inhibit phagocytic clearance and enhance delivery of nanoparticles, Science, 339 (2013) 971-975.

90. C.M.J. Hu, L. Zhang, S. Aryal, C. Cheung, R.H. Fang, L. Zhang, Erythrocyte membrane-camouflaged polymeric nanoparticles as a biomimetic delivery platform, Proc. Natl. Acad. Sci. U.S.A., 108 (2011) 10980-10985.

91. M. Wu, W. Le, T. Mei, Y. Wang, B. Chen, Z. Liu, C. Xue, Cell membrane camouflaged nanoparticles: a new biomimetic platform for cancer photothermal therapy, Int. J. Nanomed., 14 (2019) 4431-4448.

92. R. Li, Y. He, S. Zhang, J. Qin, J. Wang, Cell membranebased nanoparticles: a new biomimetic platform for tumor diagnosis and treatment, Acta Pharm. Sin. B., 8 (2018) 14-22. 
93. C. Gao, Z. Lin, B. Jurado-Sánchez, X. Lin, Z. Wu, Q. He, Stem cell membrane-coated nanogels for highly efficient in vivo tumor targeted drug delivery, Small, 12 (2016) 4056-4062.

94. T.M. Allen, Ligand-targeted therapeutics in anticancer therapy, Nat. Rev. Cancer, 2 (2002) 750-763.

95. W.X. Ren, J. Han, S. Uhm, Y.J. Jang, C. Kang, J.H. Kim, J.S Kim, Recent development of biotin conjugation in biological imaging, sensing, and target delivery, Chem. Commun., 51 (2015) 10403-10418

96. S. Jain, G. Spandana, A.K. Agrawal, V. Kushwah, K. Thanki, Enhanced antitumor efficacy and reduced toxicity of docetaxel loaded estradiol functionalized stealth polymeric nanoparticles, Mol. Pharmaceutics, 12 (2015) 3871-3884.

97. M. Li, Z. Tang, Y. Zhang, S. LV, Q. Li, X. Chen, Targeted delivery of cisplatin by LHRH-peptide conjugated dextran nanoparticles suppresses breast cancer growth and metastasis, Acta Biomater., 18 (2015) 132-143.

98. J. Li, D.J. Mooney, Designing hydrogels for controlled drug delivery, Nat. Rev. Mater., 1 (2016) 16071.

99. Y. Wang, D.S. Kohane, External triggering and triggered targeting strategies for drug delivery, Nat. Rev. Mater., 2 (2017) 17020

100. M.A.C. Stuart, W.T.S. Huck, J. Genzer, M. Müller, C. Ober, M. Stamm, G.B. Sukhorukov, I. Szleifer, V. V. Tsukruk, M Urban, F. Winnik, S. Zauscher, I. Luzinov, S. Minko, Emerging applications of stimuli-responsive polymer materials, Nat Mater., 9 (2010) 101-113.

101. S. Mitragotri, P.A. Burke, R. Langer, Overcoming the challenges in administering biopharmaceuticals: Formulation and delivery strategies, Nat. Rev. Drug Discovery, 13 (2014) 655-672.

102. M. Vicario-de-la-Torre, J. Forcada, The potential of stimuliresponsive nanogels in drug and active molecule delivery for targeted therapy, Gels, 3 (2017) 16.

103. Q.M. Zhang, W. Wang, Y.-Q. Su, E.J.M. Hensen, M.J. Serpe, Biological imaging and sensing with multiresponsive microgels, Chem. Mater., 28 (2016) 259-265.

104. X. Li, X. Su, Multifunctional smart hydrogels: Potential in tissue engineering and cancer therapy, J. Mater. Chem. B. 6 (2018) 4714-4730.

105. F. Danhier, O. Feron, V. Préat, To exploit the tumor microenvironment: Passive and active tumor targeting of nanocarriers for anti-cancer drug delivery, J. Controlled Release, 148 (2010) 135-146.

106. P. Wei, G. Gangapurwala, D. Pretzel, M.N. Leiske, L. Wang, S. Hoeppener, S. Schubert, J.C. Brendel, U.S. Schubert, Smart $\mathrm{pH}$-sensitive nanogels for controlled release in an acidic environment, Biomacromolecules, 20 (2019) 130-140.

107. Y.J. Pan, D. Li, S. Jin, C. Wei, K.Y. Wu, J. Guo, C.C. Wang, Folateconjugated poly(N-(2-hydroxypropyl)methacrylamide-comethacrylic acid) nanohydrogels with $\mathrm{pH} /$ redox dual-stimuli response for controlled drug release, Polym. Chem., 4 (2013) 3545

108. N. Deirram, C. Zhang, S.S. Kermaniyan, A.P.R. Johnston, G.K. Such, pH-responsive polymer nanoparticles for drug delivery, Macromol. Rapid Commun., 40 (2019) 1800917.

109. S. Luan, Y. Zhu, X. Wu, Y. Wang, F. Liang, S. Song, Hyaluronicacid-based ph-sensitive nanogels for tumor-targeted drug delivery, ACS Biomater. Sci. Eng., 3 (2017) 2410-2419.

110. L. Ding, Y. Jiang, J. Zhang, H.A. Klok, Z. Zhong, pH-sensitive coiled-coil peptide-cross-linked hyaluronic acid nanogels: synthesis and targeted intracellular protein delivery to CD44 positive cancer cells, Biomacromolecules, 19 (2018) 555-562.
111. H.V.P. Thelu, S. Atchimnaidu, D. Perumal, K.S. Harikrishnan, S. Vijayan, R. Varghese, Self-assembly of an aptamerdecorated, dna-protein hybrid nanogel: A biocompatible nanocarrier for targeted cancer therapy, ACS Appl. Bio Mater., 2 (2019) 5227-5234.

112. N.M. Oh, K.T. Oh, Y.S. Youn, D.-K. Lee, K.H. Cha, D.H. Lee, E.S. Lee, Poly(l-aspartic acid) nanogels for lysosome-selective antitumor drug delivery, Colloids Surf., B, 101 (2013) 298306.

113. J. Siirilä, S. Hietala, F.S. Ekholm, H. Tenhu, Glucose and maltose surface-functionalized thermoresponsive poly( $\mathrm{N}$ -Vinylcaprolactam) nanogels, Biomacromolecules, 21 (2020) 955-965.

114. L.Y. Chu, J.W. Kim, R.K. Shah, D.A. Weitz, Monodisperse thermoresponsive microgels with tunable volume-phase transition kinetics, Adv. Funct. Mater., 17 (2007) 3499-3504

115. S. Ghaeini-Hesaroeiye, H. Razmi Bagtash, S. Boddohi, E. Vasheghani-Farahani, E. Jabbari, Thermoresponsive nanogels based on different polymeric moieties for biomedical applications, Gels. 6 (2020) 20.

116. L.A. Lyon, Z. Meng, N. Singh, C.D. Sorrell, A. St. John, Thermoresponsive microgel-based materials, Chem. Soc. Rev., 38 (2009) 865

117. K. Sudhakar, K. Madhusudana Rao, M.C.S. Subha, K. Chowdoji Rao, E.R. Sadiku, Temperature-responsive poly( N -vinylcaprolactam-co-hydroxyethyl methacrylate) nanogels for controlled release studies of curcumin, Des. Monomers Polym., 18 (2015) 705-713.

118. H.G. Schild, Poly(N-isopropylacrylamide): Experiment, theory and application, Prog. Polym. Sci., 17 (1992) 163-249.

119. B. Zhang, S. Sun, P. Wu, Synthesis and unusual volume phase transition behavior of poly( $\mathrm{N}$-isopropylacrylamide)-poly(2hydroxyethyl methacrylate) interpenetrating polymer network microgel, Soft Matter, 9 (2013) 1678-1684.

120. Schwerdt, A. Zintchenko, M. Concia, N. Roesen, K.D. Fisher, L.H. Lindner, R.D. Issels, E. Wagner, M. Ogris, Hyperthermia induced targeting of thermosensitive gene carriers to tumors, Hum. Gene Ther., (2008) 081015093227032.

121. N.S. Rejinold, K.P. Chennazhi, S.V. Nair, H. Tamura, R. Jayakumar, Biodegradable and thermo-sensitive chitosan-gpoly(N-vinylcaprolactam) nanoparticles as a 5 -fluorouracil carrier, Carbohydr. Polym., 83 (2011) 776-786.

122. A.L. Daniel-da-Silva, L. Ferreira, A.M. Gil, T. Trindade, Synthesis and swelling behavior of temperature responsive K-carrageenan nanogels, J. Colloid Inter. Sci., 355 (2011) 512517.

123. X. Li, W. Yuan, S. Gu, J. Ren, Synthesis and self-assembly of tunable thermosensitive chitosan amphiphilic copolymers by click chemistry, Mater. Lett., 64 (2010) 2663-2666.

124. W. Lv, S. Liu, W. Feng, J. Qi, G. Zhang, F. Zhang, X. Fan, Temperature- and redox-directed multiple self assembly of poly( $\mathrm{N}$-Isopropylacrylamide) grafted dextran nanogels, Macromol. Rapid Commun., 32 (2011) 1101-1107.

125. T. Fernandes Stefanello, A. Szarpak-Jankowska, F. Appaix, B. Louage, L. Hamard, B.G. De Geest, B. van der Sanden, C.V. Nakamura, R. Auzély-Velty, Thermoresponsive hyaluronic acid nanogels as hydrophobic drug carrier to macrophages, Acta Biomater., 10 (2014) 4750-4758.

126. S. Ekici, P. Ilgin, S. Yilmaz, N. Aktaş, N. Şahiner, Temperature and magnetic field responsive hyaluronic acid particles with tunable physical and chemical properties, Appl. Surf. Sci., 257 (2011) 2669-2676

127. Y. Xia, X. He, M. Cao, C. Chen, H. Xu, F. Pan, J.R. Lu, Thermoresponsive microgel films for harvesting cells and cell sheets, Biomacromolecules, 14 (2013) 3615-3625. 
128. Q. Luo, P. Liu, Y. Guan, Y. Zhang, Thermally induced phase transition of glucose-sensitive core-shell microgels, ACS Appl. Mater. Inter., 2 (2010) 760-767.

129. K. Fujimoto, T. Takahashi, M. Miyaki, H. Kawaguchi, Cell activation by the micropatterned surface with settling particles, J. Biomater. Sci., Polym. Ed., 8 (1997) 879-891.

130. H. Wang, J. Yi, S. Mukherjee, P. Banerjee, S. Zhou, Magnetic/ NIR-thermally responsive hybrid nanogels for optical temperature sensing, tumor cell imaging and triggered drug release, Nanoscale, 6 (2014) 13001-13011.

131. M.D. Krebs, R.M. Erb, B.B. Yellen, B. Samanta, A. Bajaj, V.M Rotello, E. Alsberg, Formation of ordered cellular structures in suspension via label-free negative magnetophoresis, Nano Lett., 9 (2009) 1812-1817.

132. E.A. Lee, H. Yim, J. Heo, H. Kim, G. Jung, N.S. Hwang, Application of magnetic nanoparticle for controlled tissue assembly and tissue engineering, Arch. Pharmacol Res., 37 (2014) 120-128.

133. H. Perea, J. Aigner, J.T. Heverhagen, U. Hopfner, E. Wintermantel, Vascular tissue engineering with magnetic nanoparticles: seeing deeper, J. Tissue Eng. Regener. Med., 1 (2007) 318-321

134. A.M. Pavlov, B.G. De Geest, B. Louage, L. Lybaert, S. De Koker, Z. Koudelka, A. Sapelkin, G.B. Sukhorukov, Magnetically engineered microcapsules as intracellular anchors for remote control over cellular mobility, Adv. Mater., 25 (2013) 6945-6950.

135. L.J.D. Valle, A. Díaz, J. Puiggalí, Hydrogels for biomedical applications: Cellulose, chitosan, and protein/peptide derivatives, Gels. 3 (2017) 27.

136. E. Jooybar, M.J. Abdekhodaie, M. Karperien, A. Mousavi, M. Alvi, P.J. Dijkstra, Developing hyaluronic acid microgels for sustained delivery of platelet lysate for tissue engineering applications, Int. J. Biol. Macromol., 144 (2020) 837-846.

137. L. Kumar Meena, H. Rather, D. Kedaria, R. Vasita, Polymeric microgels for bone tissue engineering applications - a review, Int. J. Polym. Mater. Polym. Biomater., 69 (2020) 381-397.

138. J.P. Newsom, K.A. Payne, M.D. Krebs, Microgels: Modular, tunable constructs for tissue regeneration, Acta Biomater. 88 (2019) 32-41.
139. M. Fan, J. Yan, H. Tan, Y. Miao, X. Hu, Magnetic biopolymer nanogels via biological assembly for vectoring delivery of biopharmaceuticals, J. Mater. Chem. B, 2 (2014) 8399-8405.

140. Q. Zhang, J. Colazo, D. Berg, S.M. Mugo, M.J. Serpe, Multiresponsive nanogels for targeted anticancer drug delivery, Mol. Pharm., 14 (2017) 2624-2628.

141. S. Lou, S. Gao, W. Wang, M. Zhang, J. Zhang, C. Wang, C. Li, D. Kong, Q. Zhao, Galactose-functionalized multi-responsive nanogels for hepatoma-targeted drug delivery, Nanoscale, 7 (2015) 3137-3146.

142. R.B.K.C., B. Thapa, P. Xu, pH and redox dual responsive nanoparticle for nuclear targeted drug delivery, Mol. Pharmaceutics, 9 (2012) 2719-2729.

143. H. Yang, Q. Wang, S. Huang, A. Xiao, F. Li, L. Gan, X. Yang, Smart $\mathrm{pH} /$ redox dual-responsive nanogels for on-demand intracellular anticancer drug release, ACS Appl. Mater. Inter., 8 (2016) 7729-7738

144. D. Zhou, S. Liu, Y. Hu, S. Yang, B. Zhao, K. Zheng, Y. Zhang, P. He, G. Mo, Y. Li, Tumor-mediated shape-transformable nanogels with $\mathrm{pH} /$ redox/enzymatic-sensitivity for anticancer therapy, J. Mater. Chem. B, 8 (2020) 3801-3813.

145. F. Mahmoodzadeh, M. Ghorbani, B. Jannat, Glutathione and $\mathrm{pH}$-responsive chitosan-based nanogel as an efficient nanoplatform for controlled delivery of doxorubicin, J. Drug Delivery Sci. Technol, 54 (2019) 101315.

146. F. Li, H. Yang, N. Bie, Q. Xu, T. Yong, Q. Wang, L. Gan, X. Yang, Zwitterionic temperature/redox-sensitive nanogels for nearinfrared light-triggered synergistic thermo-chemotherapy, ACS Appl. Mater. Inter., 9 (2017) 23564-23573.

147. D. Han, X. Tong, Y. Zhao, Block copolymer micelles with a dual-stimuli-responsive core for fast or slow degradation, Langmuir, 28 (2012) 2327-2331.

148. Z. Cao, X. Zhou, G. Wang, Selective release of hydrophobic and hydrophilic cargos from multi-stimuli-responsive nanogels, ACS Appl. Mater. Inter., 8 (2016) 28888-28896.

149. Digital Human for Drug Development (DHD2) (2014) [cited August, 2020] available at http://xtal.ipph.purdue.edu/ DHD2/. 